\title{
¿PODRÍA SUPRIMIRSE EL SENADO ESPAÑOL MEDIANTE LA TÉCNICA DE LA REFORMA CONSTITUCIONAL? (UNA PRIMERA APROXIMACIÓN AL PROBLEMA PRÁCTICO DESDE LAS CIENCIAS CONSTITUCIONALES) ${ }^{1}$ (II)
}

\author{
JAVIER RUIPÉREZ ALAMILLO \\ Catedrático de Derecho Constitucional \\ Universidad de La Coruña
}

SUMARIO

I. Introducción.

II. Consideraciones acerca del concepto de «Cámara de los Estados» en el contexto de la clásica Teoría Constitucional General del Estado Políticamente Descentralizado.

III. Las tesis que consideran la existencia de la Cámara de representación territorial como el contenido esencial del concepto mismo de Estado Federal, y acerca de sus consecuencias para el ejercicio de la actividad constituyente.

IV. La concepción de la Cámara de los Estados como un instrumento propio del federalismo, pero ajeno a su manifestación estructural «Estado Políticamente Descentralizado».

V. Algunas reflexiones sobre la aparición histórica de la Cámara de los centros autónomos de decisión política democrática y legítima, o de la misma como indiscutible manifestación de lo que La Pergola denomina

1 Los tres primeros apartados de este trabajo se publicaron en el número 34 de Teoría y Realidad Constitucional, 2014. 
«Residui contrattualistici» en los ordenamientos constitucionales federales.

VI. Conclusiones provisionales: la difícil tarea de conjugar la posible supresión del Senado con la necesaria participación de las Comunidades Autónomas en el proceso de toma de decisiones políticas fundamentales en el Estado Políticamente Descentralizado.

\section{LA CONCEPCIÓN DE LA CÁMARA DE LOS ESTADOS COMO UN INSTRUMENTO PROPIO DEL FEDERALISMO, PERO AJENO A SU MANIFESTACIÓN ESTRUCTURAL «ESTADO POLÍTICAMENTE DESCENTRALIZADO»}

Bien distinta es la tesis mantenida por el insigne constitucionalista positivista francés Durand. Lo que, además, no podría ser de otra manera. Y, en cualquier caso, a ningún estudioso de las Ciencias del Derecho del Estado puede resultarle sorprendente que esto sea así.

De todos los que pretenden alcanzar una ponderada y cabal comprensión del Estado Políticamente Descentralizado es, sin duda, bien conocido que operó Durand en sus trabajos desde la concepción material del Estado Federal. Circunstancia que, en último extremo, le lleva a considerar, coincidiendo en ello con el criterio de, verbi gratia, Friedrich, La Pergola, de Vergottini y De Vega, que la única circunstancia que permite, en realidad, definir al Estado Políticamente Descentralizado es la de que, además del hecho de que, como ya había advertido Wheare, el Constituyente hubiese consagrado la autonomía como un principio estructural del Estado, en él tanto la organización política central como los miembros tienen garantizada, de una manera muy básica en virtud del principio de rigidez constitucional debidamente asegurado a través de la articulación algún mecanismo de control de constitucionalidad, su existencia y subsistencia política en el futuro.

Porque esto es así, nada de particular tiene que entienda este ilustre constitucionalista que, por más que se trate de una solución normativa generalizada en el Derecho Constitucional federal comparado, la Cámara de representación territorial no puede ser tenida como uno de los caracteres estructurales básicos de esta concreta forma territorial del Estado. Pero, e importa advertirlo, y de manera inmediata, no es sólo esto. La construcción doctrinal de Durand va mucho más allá de esta consideración. En efecto, lo que se desprende de los escritos de Durand es, y de modo inequívoco, que éste no procede meramente a decretar el carácter superestructural de la Cámara de los Estados, en el sentido de que su existencia resulta indiferente para la atribución de la naturaleza federal a una determinada estructura estatal. Por el contrario, lo que 
mantiene Durand es que la constitucionalización de la Cámara de los Estados no es más que el más manifiesto y patente intento por parte del Constituyente de mantener una institución que adquiere su máxima entidad y su total y absoluta justificación en las Confederaciones de Estados, y aplicarla a una realidad política y jurídica que, aunque articulada sobre la misma técnica organizativa, tiene ciertamente muy poco que ver con aquélla, como ocurre con el Estado Federal.

No hace falta realizar un sobrehumano esfuerzo intelectual para comprender cuál es el punto de partida, inexorable, para la construcción de Durand. Para todos debiera ser evidente que su formulación está erigida sobre las categorías conceptuales desde las que la más clásica Teoría del Estado y de la Constitución procedió, desde siempre, a establecer la distinción entre las dos variantes históricas del federalismo. Esto es, lo que ocurre es que, frente a la confusión, ya señalada, generada por la puesta en circulación del concepto de «Estado Federativo» por Zorn y Borel, o la no menor provocada por la idea kelseniana de que Staatenbund y Bundesstaat se diferencian tan sólo por el mayor grado de descentralización política que opera en la primera, sigue defendiendo Durand que entre ambas existe una muy grande, substancial, profunda e insalvable diferencia cualitativa, la cual determina su muy diferente naturaleza jurídica. Divergencia que se concreta en que mientras que la primera se presenta como una auténtica Unión de Derecho International, el segundo se configura como una Unión de Derecho Constitucional. Diferenciación ésta en la que, en cuanto que ello servirá para obtener una más correcta comprensión de la tesis que ahora nos ocupa, acaso resulte conveniente detenerse.

No es éste el momento oportuno para detenernos a realizar una exposición exhaustiva y pormenorizada sobre todos y cada uno de los caracteres que la Teoría del Estado y de la Constitución ha predicado de la Confederación en orden a definirla. Lo que nos interesa es tan sólo el señalar las razones que justifican la opinión de Durand, según la cual la existencia de la Cámara de las colectividades-miembro se encuentra completamente justificada en el supuesto de la Confederación, pero no, y bajo ningún concepto en el de la Federación.

Es menester recordar que, superados y abandonados de una manera general los planteamientos mantenidos por Zorn, existe un muy amplio acuerdo entre los estudiosos de las Ciencias del Estado y de las Ciencias del Derecho del Estado en cuanto a lo que es, y significa, la forma política general «Confederación de Estados». Existió, en efecto, un muy amplio, por no decir unánime, acuerdo entre los autores de la clásica Teoría del Estado y de la Constitución en conceptuar a la Confederación en torno al tres grandes rasgos distintivos, a través de los cuales, y como fue, y sigue siendo, el método más extendido en el ámbito de los estudios de una Teoría del Estado y de la Constitución consciente de sus propios contenidos y de su propia función (A. La Pergola), se sentaban definitivamente las diferencias existentes entre esta forma política y la alianza internacional, por un lado, y entre la Staatenbund y el Bundesstaat, por otro. A saber: 
1. Definió la doctrina clásica a la Confederación como una unión constituida, con vocación de ser perpetua — en el sentido de, como escribe, por ejemplo, La Pergola, lo característico del confederantismo es que el «pacto une a los miembros con un vínculo perpetuo de unión política (el «eviger Bund», «jurado» por los cantones, como se dice en la helvética Eidgenössenschaft), que se refleja, al menos potencialmente, en toda la esfera de sus actividades estatales»—, para la satisfacción de unos fines generales, tenga reconocida la personalidad jurídica internacional e interna, así como el que esté dotada de una organización institucional propia y permanente que no sólo representa al conjunto de los Estados particulares confederados, sino que adopta decisiones, jurídicas y políticas, que resultan de obligado cumplimiento para estos últimos. La Unión de Derecho International o, si se prefiere, y por utilizar la terminología empleada por Le Fur, el «Sistema de Estados» quedaba, de esta suerte, absolutamente diferenciada de las meras agrupaciones de Estados soberanos bajo la fórmula de la alianza internacional.

2. El segundo de los rasgos definidores de la Confederación de Estados que, con las únicas excepciones relevantes de Calhoun y von Seydel ${ }^{2}$, propuso la clásica Teoría del Estado y de la Constitución para conceptualizar la Staatenbund adquiere su máximo significado en tanto en cuanto el mismo sirve para proceder a diferenciar las dos manifestaciones históricas del federalismo. En este sentido, se dirá que, de un modo muy diverso a lo que sucede con el nacimiento del Estado Federal, los efectos generados para la Comunidad Internacional por la entrada en escena de una nueva Unión Derecho International son bastante relativos. Afirmación ésta que, sin duda, requiere alguna aclaración.

Es verdad que la creación de una Confederación comporta, al igual que sucede con la puesta en marcha de la otra manifestación estructural posible de las Unión de Derecho International, la entrada en escena de un nuevo sujeto político y jurídico, el cual, siempre y cuando cumplan las condiciones establecidas al efecto por el Derecho Internacional Público, podrá ser reconocido por parte de la Comunidad Internacional como uno de sus miembros y, con ello, otorgándole el status de sujeto del Derecho Internacional. Ahora bien, es lo cierto, sin embargo, que, a diferencia de lo que sucede en el supuesto del nacimiento de un nuevo Bundesstaat, la entrada en escena de la organización común, no supone, como afirma de manera prácticamente unánime la doctrina del Derecho del Estado, ni la

2 Cfr. J. C. Calhoun, Libertad y Unión. La Teoría de la Confederación, Madrid, 2010. M. Von Seydel, «Der Bundesstaatsbegriff. Eine Staatsrechtlsiche Untersuchung», Tubinger Zeitschrift, vol. XXVIII (1872); Grundzüge einer allgemeinen Staatslebre, Würzburg, 1873; Staatsrechtliche und politische Abbandlungen, Friburgo i. B-Leipzig, 1883; Commentar zur Verfassung-Urkunde für das Deutsche Reich, Friburgo i B.-Leipzig, 1897, 2. ${ }^{\mathrm{a}} \mathrm{ed}$. 
aparición de un nuevo Estado por encima de las colectividades particulares que la formaron, ni tampoco la disolución, al modo descrito por Althussius, en ese nuevo ente de las preexistentes Comunidades Políticas estatales. Estas últimas, por el contrario, seguirán manteniendo su existencia y, en definitiva, seguirán presentándose, junto con la nueva Confederación, pero de manera diferenciada e individualmente, como auténticos sujetos del Derecho Internacional.

Aparece, de este modo, en opinión de la mayoría de los autores clásicos, una substancial distinción entre las dos manifestaciones históricas de las organizaciones estatales del federalismo. Distinción que, según nuestro parecer, continúa, no obstante esa cierta confusión generada por la interpretación, _claramente deudora de los planteamientos de Mancini-, realizada por el custodio constitucional en relación con el art. 149.1. 3. ${ }^{\text {a del Texto español }}{ }^{3}$, gozando de una plena entidad y realidad, así como de una absoluta operatividad en orden a determinar la verdadera naturaleza jurídica de una determinada estructura estatal políticamente descentralizada. La misma se concreta en que mientras que en el caso de la Confederación, en tanto en cuanto se trata de una Unión de Derecho International, deviene absolutamente lógico el que las colectividades particulares sigan presentándose como titulares del treaty-making power, no sucede lo mismo, empero, y porque ahora nos encontramos una Comunidad Política Constitucional, en el supuesto del Estado Federal. De suerte tal que bien puede dársele la razón a Burgess cuando afirmaba que, en cuanto que técnica inherente al confederantismo, la atribución por parte del Pouvoir Constituant federal de la competencia para celebrar Tratados Internacionales con terceros Estados a todos y cada uno o, en su caso, a alguno de los centros autónomos de decisión política democrática y legítima que integran el Estado Políticamente Descentralizado, sería una decisión que, aunque indisputablemente legítima, habría de ser reputada como un completo y patente absurdo. Lo que, por lo demás, no ha de ser muy difícil de comprender. Basta, en este sentido, con tomar en consideración que en el caso del Estado Federal, el único sujeto que, por tener reconocida la personalidad jurídica internacional, puede participar en el tráfico jurídico internacional y, por ello mismo, obligarse al cumplimiento de las obligaciones internacionales derivadas de los convenios cerrados con otros Estados, es la propia Federación en su conjunto, y en su condición de único sujeto del Derecho Internacional ${ }^{4}$.

3 Cfr. STC $165 / 1994$, de 26 de mayo, F. J. $4 .^{\circ}, 5 .^{\circ}$ y $6 .^{\circ}$.

4 Cfr. H. Mosler, «Die völkerrechtliche Wirkung Bundesstaatlicher Verfassungen. Eine Untersunchung zum Völkerrecht und zum vergleichenden Verfassungsrecht», en la obra colectiva Festschrift zum Richard Thoma, Tubinga, 1950. 
Nada de particular tiene, en tales circunstancias, que la problemática de las relaciones internacionales se haya convertido en uno de los principales factores para que, a través de lo que Laband ${ }^{5}$ y Jellinek bautizaron con el término de «Wandlung» o «Verfassungswanlung», se haya verificado en el marco del Derecho Constitucional Federal comparado un progresivo, y paulatino, incremento del poder por parte de la organización política central, en detrimento del ámbito de autogobierno del que primigeniamente disfrutaron las colectividades particulares. Lo que se explica por cuanto que el resto de los miembros de la Comunidad Internacional mostrarán una más que sobresaliente resistencia para establecer obligaciones contractuales con unos entes político territoriales que, en cuanto que no son sujetos del Derecho Internacional, no son directamente responsables del incumplimiento de aquellas obligaciones, quedando, en consecuencia, cumplimiento al albur de la voluntad de la organización central del Estado Políticamente Descentralizado.

3. El último de los criterios que de manera generalizada ha sido utilizado por la Teoría del Estado y de la Constitución para caracterizar a la Confederación, y, al mismo tiempo, distinguirla definitivamente del Estado Federal, se concreta en la problemática de quién es el titular de la soberanía estatal en una y otra forma política. Es menester aclarar, y de manera inmediata, que, aunque partiendo de las más diversas concepciones sobre la soberanía y desde unos muy distintos presupuestos metodológicos para su estudio, la solución dada a este interrogante por la mayoría de los autores de la doctrina clásica termina siendo de alguna suerte idéntica. En efecto, es el criterio general el de afirmar que, como ya ha quedado consignado, la determinación de a quién corresponde la titularidad del ejercicio de la soberanía se erige en un elemento nuclear para poder llevar a cabo la diferenciación precisa entre la Staatenbund y el Bundesstaat. De esta suerte, se dirá que lo característico y lo propio del Estado Políticamente Descentralizado es el que, en él no puede haber, por utilizar la ya conocida tesis de Friedrich, más soberano que el Poder Constituyente del Pueblo estatal que aprobó y estableció la Constitución por la que se rige la vida jurídica y política de la Unión Constitucional de la que se trate. E importa señalar que esto es así incluso cuando el Estado Federal surge como consecuencia de un proceso de unión y progresiva centralización de unos preexistentes Estados soberanos, independientes y a los que, hasta ese momento, les correspondía la condición de ser lo que, por ejemplo, Kunz denominaba «Staat im Sinne der Völkerrechts». Lo que, a nuestro juicio, resulta fácilmente comprensible. Basta con tomar en considera-

5 Cfr. P. Laband, Die Wandlungen der deutschen Reichverfassung, Dresde, 1895; "Die geschichtliche Entwicklung der Reichverfassung seit der Reichgründung», Jabrbuch des öffentlichen Recthts, vol. 1 (1907). 
ción que la verificación de lo que Wise denominaba «momento del pacto social», o, si se prefiere, la culminación de aquel «nationale Tat» del que hablaban Zorn y Jellinek comporta tanto la disolución de los preexistentes Cuerpos Políticos independientes en una única Comunidad Política estatal, como la renuncia voluntaria por parte de todos y cada uno de los anteriores Estados a la titularidad de unos derechos de soberanía, para asumir la condición de ser, al igual que la organización política central, tan sólo titulares de derechos de autonomía.

Todo lo contrario sucede en la Staatenbund. Lo que se debe al hecho de que la conclusión del Tratado por el que nace la Confederación no supone la conformación de un Cuerpo Político único. Porque esto es así, fue prácticamente unánime la doctrina clásica en la aceptación de la idea de que la creación de la que, sin disputa, se presenta como la forma más perfecta y acabada de las Uniones de Estado de Derecho Internacional comporta, sí, y como, con claridad meridiana y acierto pleno, afirmó Zorn, que las comunidades confederadas experimentarán ciertas limitaciones en el ejercicio de sus facultades soberanas, pero no, y muy en contra de lo aseverado por Meyer, la pérdida del status de sujetos titulares del ejercicio de la soberanía estatal.

Ninguna dificultad debiera existir para entender porque Durand consideró como un elemento absoluta y definitivamente necesario de la forma política «Confederación de Estados» la existencia en ella de una Cámara de representación territorial. Como tampoco debiera haberla para comprender que lo mismo se deriva de la naturaleza de la Staatenbund como una unión no, y bajo ningún concepto, de ciudadanos sino, por el contrario, de Estados soberanos.

Tampoco habría de ser muy difícil de comprender que es por esa naturaleza que corresponde a la Confederación de ser una verdadera unión de Estados soberanos, lo que determina el que en este supuesto la existencia de la Cámara de representación territorial adquiera la condición de presentarse como una exigencia democrática. Lo que se explica por el hecho de que, al menos desde Solón, constituyó una constante del pensamiento político democrático el que el Derecho sería tan sólo jurídicamente obligatorio y vinculante cuando sus normas hubiesen sido aprobadas con la participación, directa o indirecta, de aquéllos que son los destinatarios directos de sus mandatos.

Fácil tendría que ser, asimismo, admitir que, situados en los esquemas conceptuales de Durand, podamos nosotros afirmar que también encontraría un perfecto acomodo la Cámara de los Estados en la actual Unión de Derecho International europea en cuanto que manifestación estructural de la que La Pergola ha conceptuado como una inequívoca e indiscutible «Confederación de Estados en su forma moderna». Lo que, en definitiva, vendría justificado por la toma en consideración de la que, sin disputa posible alguna, constituye la mayor de las singularidades de la actual Unión Europea en el contexto de la clásica tipología de las formas territoriales del Estado. Nos referimos, innecesario debiera ser aclararlo, a la aparición de 
la llamada «ciudadanía europea». Es menester tomar en consideración, en este sentido, que la actual Unión Europea pretende erigirse como una forma política y jurídica de organización interestatal caracterizada por ser al mismo tiempo, y por igual, una unión real entre ciudadanos y entre Estados soberanos.

Es, naturalmente, esta última consideración la que nos sirve para justificar nuestra anterior afirmación. Esto es, que es, particular y precisamente, en ella donde adquiere su auténtica y real significación y sentido la idea de que en toda organización estatal organizada de conformidad con la técnica del federalismo, el proceso de elaboración, discusión y aprobación de las decisiones políticas fundamentales de verificarse con el concurso de, por volver a la ya conocida terminología empleada por Carré, la de la Cámara federal popular y la Cámara de los Estados. Al fin y al cabo, lo que sucede es que es que en la actual Unión Europea, que sigue siendo una Unión de Derecho International, los destinatarios del que hoy se denomina «Derecho de la Unión Europea» son tanto, y por igual, los ciudadanos comunitarios, como las autoridades políticas de los llamados Estados comunitarios.

Siguiendo este razonamiento, fácil habría de ser el entender el motivo por el cual Durand considera que la Cámara de representación territorial es un instituto ajeno al Estado Federal. La razón es, al menos a nuestro juicio, fácilmente comprensible. Y éste es el que se deriva de la naturaleza del Bundesstaat como auténtica unión de ciudadanos. Lo que, traducido en otros términos, significa que Durand parte la tesis de que la Federación es tan sólo una de las muchas manifestaciones estructurales posibles del Estado Constitucional.

No hace falta ser en exceso perspicaz para comprender que las conclusiones a las que, en cuanto a la repercusión que tiene el concepto mismo de Cámara de los Estados para el ejercicio de la actividad constituyente, puede únicamente llegarse desde esta construcción que ahora nos ocupa son bien distintas a las que veíamos en el apartado anterior. Veámoslo, aunque sea de manera sintética.

Es menester recordar que para Durand la Cámara de representación territorial es un elemento superestructural, cuya constitucionalización ni añade, ni resta federalidad al sistema. Porque esto es así, evidente resulta que, para Durand, cuando, en la realización del «el momento del pacto social», los hombres y mujeres que convienen en convertirse en los futuros ciudadanos de esa nueva Comunidad Política estatal fundada o refundada, así como los modos y las formas en los que quieren ser gobernados en el futuro, y deciden organizar el Estado como una auténtica Federación, el Pouvoir Constituant encargado de dar expresión jurídica a estas decisiones en el más alto nivel normativo del Cuerpo Político se verá, ineludiblemente, limitado en el contenido material de su voluntad en lo que hace a la adopción de una u otra forma territorial del Estado. Aunque, y esto es importante ponerlo de manifiesto, con una grandísima libertad en cuanto a la determinación de la concreta manifestación estructural posible de aquél. Ahora bien, si esto es así, no es menos cierto que el Constituyente originario en modo alguno se encontrará obligado a establecer que la legislación federal haya de ser aprobada 
mediante el concurso de la voluntad de la Cámara Federal Popular y de la Cámara de los Estados.

E importa señalar que, de conformidad con la tesis que ahora nos ocupa, no estaría obligado a sancionar el que generalmente suele considerarse el modelo institucional típico del Estado Políticamente Descentralizado, ningún Pouvoir Constituant revolucionario. No lo estaría, en efecto, ni siquiera el Legislador Constituyente que se encarga de actuar la facultad constituyente en el supuesto de que el Estado Federal haya nacido como consecuencia de un proceso de progresiva y paulatina unificación y centralización de una preexistente Staatenbund. Lo que, en última instancia, se explicaría por su naturaleza de poder absoluto, soberano e ilimitado en el contenido, formal y material de su voluntad, cuya mera aparición conlleva la derogación de los distintos Textos Constitucionales por los que regía la vida de las distintas colectividades confederadas. Mucho menos, y en consecuencia, habría de estarlo un Constituyente revolucionario que lo que hace es proceder a la transformación de un preexistente Estado Unitario en una de las múltiples manifestaciones estructurales posibles de la forma política «Unión de Estados de Derecho Constitucional».

Otro tanto, y a pesar de que éste si se encuentra limitado en el ejercicio de la facultad constituyente por la obligación de actuar siempre con respeto a la voluntad del Pouvoir Constituant soberano, ocurre cuando, por haber sido ya creada la Federación y, además, haber entrado en vigor la Constitución federal, la decisión sobre el futuro de la Cámara de los Estados recae en el poder de reforma constitucional. Porque, de acuerdo con Durand, la existencia de este órgano no constituye un elemento esencial, basilar, nuclear, y central del Estado Políticamente Descentralizado, inconcuso resulta que ahora la existencia de la Cámara de representación territorial no puede entenderse incluida entre esas materias que, en cuanto que forman parte de la fórmula política (P. Lucas Verdú) o, si se prefiere, y por recurrir a la terminología hesseniana, de los fundamentos de orden de la Comunidad Política, integran el núcleo estable e irreformable de la Constitución, y, por lo tanto, excluidas de la capacidad de acción de los poderes constituidos. Incluido entre ellos, y pese a su carácter extraordinario, el Legislador constitucionalmente facultado para proceder a la modificación formal del Código Jurídico-Político Fundamental.

De esta suerte, nos encontramos con que, en la medida en que, salvo naturalmente que la existencia de este órgano federal con especiales vínculos con las colectividades-miembro, y además se incluya en ella el modelo concreto primigeniamente constitucionalizado, se encuentre incorporada a una cláusula de intangibilidad, no estamos en presencia de un límite material absoluto a la revisión constitucional, no es ya que, como, ya lo vimos, admitía Hesse, el Legislador de reforma pueda proceder, de manera absolutamente libre, a substituir el modelo de Cámara de los Estados diseñado por el Constituyente originario por el modelo opuesto. Por el contrario, lo que sucede es que, como se desprende con toda nitidez de la construcción de Durand, el poder de reforma podría, asimismo de ma- 
nera libre, consciente y voluntaria, proceder a llevar a cabo una modificación del Texto Constitucional que tuviese por objeto la supresión del órgano primigeniamente consagrado. Que ello sea así, es algo que, en nuestra opinión, no debe ser muy difícil de comprender. En efecto, lo que sucede es que, de un modo bien diverso a lo que se desprendía de la tesis que vimos en el apartado anterior, ahora se entiende que la supresión del Senado o del Consejo Federal no comporta, ni mucho menos, y bajo ningún concepto, ni un cambio en el modelo del Estado Federal consagrado por el Poder Constituyente en el momento de aprobar el Código Constitucional concreto y determinado por el que se rige la vida de esa determinada estructura estatal, ni tampoco el que ese Estado Políticamente Descentralizado observado desde una óptica abstracta y general se transforme, como consecuencia de la revisión constitucional, en una de las manifestaciones estructurales posibles de la forma territorial del Estado que conocemos con el término de «Estado Unitario».

\section{ALGUNAS REFLEXIONES SOBRE LA APARICIÓN HISTÓRICA DE LA CÁMARA DE LOS CENTROS AUTÓNOMOS DE DECISIÓN POLÍTICA DEMOCRÁTICA Y LEGÍTIMA, O DE LA MISMA COMO INDISCUTIBLE MANIFESTACIÓN DE LO QUE LA PERGOLA DENOMINA «RESIDUI CONTRATTUALISTICI» EN LOS ORDENAMIENTOS CONSTITUCIONALES FEDERALES}

Conocidas las dos posturas doctrinales extremas sobre el sentido y significado de la Cámara de los Estados, es cuando comenzamos ya a estar en condiciones de tratar de responder a la cuestión de si sería, o no, viable y factible el suprimir el actual Senado español a través de la apertura de un proceso de reforma constitucional. Y, siendo fieles a la idea de que tan sólo puede obtenerse una ponderada y cabal comprensión del Derecho Constitucional vigente en un determinado Estado y, al mismo tiempo satisfacer esa dimensión práctica que constituye la principal misión de una Teoría del Estado y de la Constitución consecuente con su propia función, es atendiendo a los procesos de conceptualización y fundamentación, estimamos que la única manera posible de pronunciarse adecuadamente sobre cuál de las dos concepciones resultan más correcta es, y sólo puede ser, la de tomar en consideración las circunstancias históricas que determinaron la entrada en escena del concepto mismo de Cámara de los Estados.

Si así lo hacemos, es tan sólo una la conclusión a la que podemos llegar. Y ésta es la de que la genéricamente llamada Cámara de los Estados hizo su entrada en escena en el contexto del proceso de formación histórica de los dos grandes modelos paradigmáticos de la forma política Estado Políticamente Descentralizado, los Estados Unidos de América y la Federación alemana, y que lo hizo, además, como una inequívoca manifestación de lo que La Pergola ha definido con el término de «Residui contrattualistici» en los ordenamientos constitucionales de 
los Estados Federales que han nacido como consecuencia de un proceso de paulatina y progresiva unificación y centralización de una preexistente Confederación de Estados. Figura que ha de ser entendida, naturalmente, en el sentido de que en estos supuestos, y a pesar de que también aquí se reconoce a quien desarrolla la función constituyente originaria la condición de ser un sujeto fáctico y político-existencial que ejerce un poder absoluto, soberano e ilimitado en el contenido de su voluntad, es lo cierto, sin embargo, que en no pocas ocasiones las decisiones adoptadas por el Poder Constituyente federal se encuentran condicionadas por la situación jurídica y política que existía en la etapa confederal. Y esto es, en efecto, lo que determinó el que tanto en los Estados Unidos de América, convertidos ahora en una Comunidad Política estatal única, como en el primer Estado alemán se constitucionalizase la fórmula de que el proceso de adopción de las decisiones políticas fundamentales de la Federación debía desarrollarse con la participación de una Asamblea Legislativa en la que tendrían que estar representados los ciudadanos en cuanto que Pueblo único de la naciente Unión de Derecho Constitucional, y de una segunda instancia decisoria que, configurada como una auténtica Cámara de los centros autónomos de decisión política federados, e integrada por los representantes de estos últimos, permitiese, que los miembros pudiesen incorporar su voluntad unitaria al proceso de formación de la voluntad unitaria del Estado Federal en cuanto que Cuerpo Político único. Siendo, de cualquiera de las maneras, las muy distintas concepciones sobre las que se fundamentaban la Confederación y Unión Perpetua de los Estados Unidos de América y, en particular y en cuanto que precedentes directos del Estado alemán nacido en 1871, las deutscher Bund y Norddeutscher Bund las que determinaron la definitiva constitucionalización del modelo Senado y del modelo Consejo.

\section{La influencia del Congress confederal en la regulación constitucional del Senado por parte de los Founding Fathers}

Que el Senado estadounidense puede ser considerado, perfectamente, como un claro ejemplo de esos «residuos contractualísticos» a los que se refiere La Pergola, es algo sobre lo que pueden existir muy pocas dudas. Basta para llegar a esta conclusión con tomar en consideración tanto las circunstancias que concurrieron en el desarrollo del proceso constituyente en general, como las causas últimas que condujeron a los «Hombres de Filadelfia» a consagrar aquel órgano y, al mismo tiempo, las concomitancias que existen en la regulación concreta del mismo con el régimen jurídico que tenía el viejo Congress como único órgano común de la etapa confederal de los Estados Unidos de América. Cuestiones éstas que, como se descubre con la mera lectura de la celebérrima «De la Démocratie en Amérique» de A. de Tocqueville, se encuentran íntimamente relacionadas.

Nadie puede ignorar, este respecto, que reunida, el 25 de mayo de 1787, en la Convención de Filadelfia, y entendiendo sus miembros que su función no debía 
ser la que se le había encomendado en el momento de su convocatoria, sino la de, como escribió Hamilton, «deliberar sobre una nueva Constitución para los Estados Unidos de América», se hizo pronto visible que no todos los delegados en la Convención tenían la misma opinión sobre el modo en que debía configurarse y articularse la nueva y naciente República estadounidense. Antes al contrario, nos encontramos con que en el seno de la Constituyente existieron tres grandes grupos que, en todo caso, defendían muy diferentes modelos respecto del régimen constitucional que debían crear.

Así, nos encontramos, en primer lugar con que aproximadamente un tercio de los representantes de los distintos Estados hasta entonces confederados podían ser agrupados bajo el rótulo, más que de «federalistas» como lo fueron inicialmente, de «nacionalistas». Entre los que integraban este grupo podemos destacar a Washington, Hamilton, Randolph, King, Pinckney, Wilson y Morris. Su plan de acción se fundamentaba en el llamado «Plan de Virginia» — en cuyos planteamientos, interesa resaltarlo, se mostraría conforme el posteriormente secesionista Calhoun hasta 1824-. Éste, expuesto de una manera muy básica, aunque, naturalmente, sin caer en el un más que lamentable error de o bien proceder a la simplificación de lo complejo, o bien a la complicación de lo simple, se concretaba en la defensa de que la nueva Comunidad Constitucional estadounidense no sólo debía abandonar el status de Unión de Derecho International, sino que, al mismo tiempo, debía configurarse como un Estado Unitario, además en una de las manifestaciones estructurales posibles de este más centralizadas.

En segundo término, nos encontramos con el grupo que podemos identificar con el término de «federalistas». Entre quienes se encontraban Sherman, Martín, y Patterson. Su actuación respondía a lo acordado en el «Plan de New Jersey». En él, lo que se va a defender es que, aunque se estaba procediendo a la creación de una Comunidad Constitucional, la articulación concreta del nuevo Estado estadounidense debía efectuarse respetando los esquemas propios del confederantismo. De ahí, precisamente, que propugnasen un más que sobresaliente fortalecimiento de los derechos de los Estados, así como un correlativo debilitamiento de los poderes de la organización política central respecto de lo proyectado por el grupo anterior.

Por último, estaría el grupo de los «unionistas», que estaba integrado de manera fundamental por los representantes en la Convención de los Estados de nueva Inglaterra y los de los tres Estados del Sur. Las pretensiones de estos delegados eran, como nos dice Mathiot, equidistantes respecto de lo propugnado por los otros dos grupos. Esto es, los representantes que defendían esta tendencia unionista compartían con los nacionalistas la idea de que se presentaba como una necesidad imperiosa, e ineludible, la del fortalecimiento de la organización común de la unión. Discrepaban, sin embargo, en cuanto al modelo de forma territorial del Estado que habría de deparar el atender adecuada y obligatoriamente a esta perentoria exigencia. En efecto, ocurre que mientras que para los nacionalistas la única manera posible de hacer frente a la tarea de todos y cada uno de los 
inconvenientes que se habían puesto de relieve como consecuencia de la configuración jurídica de los Estados Unidos como una Unión de Derecho International, era la de que la Convención de Filadelfia elaborase un Código Constitucional, en virtud del cual aquéllos se organizase según la técnica propia del Estado Unitario, entendieron, por el contrario, los unionistas que ese nuevo Estado único, debía mantener a las preexistentes colectividades jurídicas y políticas en el status de ser unos auténticos centros autónomos de decisión política democrática y legítima. Proposición que no significaba que los unionistas compartiesen plenamente la idea de los federalistas de organizar el nuevo Estado manteniendo no pocos de los esquemas propios del confederantismo. Antes al contrario, existía una muy importante diferencia entre unos y otros. Diferencia ésta que, a la postre, se concretaba en la defensa hecha por los unionistas de la necesidad de fortalecer el poder de la organización política central.

No hace falta ser muy perspicaz para comprender que una tal composición efectiva de los delegados habría de conllevar, de modo indefectible, que fueran no pocos los asuntos en los que el acuerdo sobre la solución normativa que debía adoptarse no fuese fácil de lograr. Entre los puntos donde se hizo más evidente el desencuentro entre las distintas facciones de la Convención de Filadelfia se encontraba, y es el que realmente nos interesa destacar, la problemática de cómo organizar el Poder Legislativo federal. Lo que, en definitiva, no es más que la lógica consecuencia de las radicales y diametralmente contrarias pretensiones que defendían los nacionalistas y los federalistas.

Es menester recordar que, desechada rápida y contundentemente la tesis, minoritaria entre los Founding Fathers, de organizar el nuevo Parlamento siguiendo el ejemplo británico, fueron dos concepciones harto diferentes e, incluso, irreconciliables las que se defendieron sobre el cómo debía configurarse el Congress, concebido ahora, y de manera unánime, como el órgano encargado de desarrollar la función legislativa de la Unión Constitucional. Lo que se discutía, en realidad, era quién debía estar representado en el proceso de toma de decisiones políticas fundamentales.

Ha de tomarse en consideración, a este respecto, que las propuestas de los nacionalistas y de los federalistas eran concluyentemente irreconciliables. Los primeros, consecuentemente coherente con su idea de que la vieja Confederación y Unión Perpetua formada por las antiguas colonias británicas debía ceder paso a un Estado Unitario, propugnarían que la representación en el nuevo Congress debía corresponder a los ciudadanos en cuanto que integrantes de ese Pueblo único, y con el que, de una suerte u otra, terminaba por identificarse la propia República estadounidense creada por la voluntad, libre y consciente, de los Founding Fathers. Siendo así, fácil resulta deducir la propuesta que este grupo de convencionales realizaba para el ejercicio, y ordenado funcionamiento, de la democracia representativa en el marco de los Estados Unidos de América fundado, ahora, como un Cuerpo Político único. El primer contenido de esta propuesta se concretaba, de una manera concreta, en la idea, innegablemente tributaria del más con- 
solidado pensamiento político democrático, de que porque el Pueblo es uno, no ha lugar en el marco del Estado Constitucional a que la representación en el Parlamento se articule atribuyendo los escaños parlamentarios a los distintos estamentos a los que individuos pertenecían, o, en su caso, a los diferentes entes territoriales en los que los ciudadanos federales tenían residencia administrativa. El Parlamento estadounidense quedaba, desde esta perspectiva, configurado de acuerdo con lo que posteriormente constituirá el modelo teórico ideal, aunque sin haber encontrado jamás una materialización efectiva, de las asambleas legislativas sobre el que se edificó la relación representativa en el contexto del Estado Constitucional liberal: el Parlamento como escenario en el que se daban cita los distintos y contrapuestos intereses sociales, políticos y económicos que existían en el seno de la «sociedad civil», y que los representantes parlamentarios, a través de un proceso de discusión libre y pública ${ }^{6}$, lograban conciliar para formar la voluntad unitaria del Estado a la que se daba expresión normativa a través de la aprobación de las distintas leyes.

Por su parte, el segundo punto programático defendido por los nacionalistas se nos antoja meridiano y patente. Éste se concreta en que porque el Congreso, en cuanto que titular del Poder Legislativo federal, ha de expresar la voluntad unitaria del Pueblo federal en su conjunto, inexcusable resultaba el que el mecanismo de elección de los representantes parlamentarios de los ciudadanos tenía que ser objeto de una regulación que sólo podría ser establecida por el Derecho emanado por la organización política central.

Derivado de los dos contenidos anteriores, aparece el tercero de los mensajes del proyecto de los nacionalistas. El mismo no podría ser más claro y evidente. En la medida en que de lo que se trata en el Estado Federal es de representar la voluntad unitaria de los ciudadanos federales, la decisión de los Founding Fathers habría de comportar, constrictivamente, una más que sobresaliente transformación en cuanto al papel que correspondía a los Estados particulares en la designación de los representantes en el Congress. De esta suerte, propondrían los nacionalistas, y su tesis sería la que sería adoptada para la Cámara de Representantes, que a los efectos de designar a los miembros del Legislativo federal, los Estados debían quedar, legal y constitucionalmente, configurados como meras circunscripciones electorales.

Por último, se refirieron los nacionalistas al problema de cómo habrían de distribuirse los escaños. $Y$, en este sentido, su propuesta, se concretaba en la exigencia de que los escaños parlamentarios deberían repartirse entre las colectividades particulares atendiendo, y esto es lo que realmente resulta relevante e importante, al número de habitantes que tenía cada una de ellas.

Radical y diametralmente opuesta era la solución propugnada por los federalistas. Lo que se debía a la muy distinta concepción que tenían éstos respecto de

6 Cfr. P. DE VEGA, «El principio de publicidad parlamentaria y su proyección constitucional», Revista de Estudios Políticos, n. ${ }^{\circ} 43$. 
lo que habría de deparar y significar la transformación de la Convención de Filadelfia en una verdadera Asamblea Constituyente, con todo lo que eso entraña desde la lógica de la Teoría Democrática del Poder Constituyente del Pueblo. Admitieron, sí, los federalistas que con la aprobación de la Constitución federal, los Estados Unidos de América adquirirían el status de Estado Constitucional. El problema se presentaba en cuanto al modo en que unos y otros pretendían articular normativamente la vida de ese nuevo Estado soberano. En efecto, frente a la idea de establecer un Estado Unitario muy centralizado defendida desde el grupo que estamos identificando como nacionalistas, los federalistas patrocinarían la tesis de que la nueva y naciente República estadounidense, siendo una Comunidad Política estatal única, debía organizarse manteniéndose, no obstante, en una situación muy próxima a la que se derivaba de los esquemas jurídicos, y políticos, del confederantismo.

En tales circunstancias, a nadie puede sorprender que fuera muy otra la solución normativa que se proponía para el Congreso federal. Para éstos, la solución adecuada era la de mantener el sistema consagrado por Artículos de la Confederación y Unión Perpetua de los Estados Unidos de América. Lo que significaba que se atribuía la representación parlamentaria a los miembros, concebidos como las auténticas partes integrantes del nuevo Estado Federal. Y, en este sentido, ocurre que porque todos los Estados-miembro, en cuanto que centros autónomos de decisión política democrática y legítima, son iguales, todos habrían de designar número igual de representantes en el nuevo Congress. Se garantizaba, así, aquélla tan ansiada igualdad entre las distintas comunidades-miembro. Representación igual por la que tanto luchaban los delegados ante la Convención que representaban a los Estados con un muy bajo número de habitantes.

La conciliación entre tan encontradas posturas, no obstante ser una empresa ardua y difícil, terminó por lograrse. Y lo hizo gracias a la iniciativa de Benjamín Franklin que fue asumida por los delegados de Connecticut, y que dio origen al célebre «Compromiso de Connecticut ${ }^{7}$. En él, que, de algún modo, respondía al criterio mantenido por el grupo de los unionistas, se proponía una solución ecléctica que, por ser equidistante entre las rígidas posturas de nacionalistas y los federalistas, permitió alcanzar el consenso sobre el Parlamento federal, en tanto en cuanto, y con no poca importancia, aquel documento venía a satisfacer las aspiraciones tanto de los delegados de los Estados grandes como las de los representantes de los centros autónomos de decisión política democrática y legítima pequeños. El Profesor Mathiot se ha referido a ello en los siguientes términos: el consenso fue posible en tanto en cuanto que «Consistía este compromiso en dividir el Congreso de la Unión, [...], en dos Cámaras, una de las cuales representaría a la nación reflejando, por consiguiente, la importancia de los Estados, y la otra

7 Cfr. G. F. HoAr, «The Connecticut Compromise», Proceedings of the American Antiquarian Society, vol. 15 , n. ${ }^{\circ} 2$ (1902). 
Cámara, la que se convertiría en el Senado, representaría a los Estados en pie de igualdad».

La influencia de la etapa confederal se presenta, en tales circunstancias, como algo indiscutible. Y no sólo en cuanto a las competencias que los Hombres de Filadelfia atribuyeron a esta nueva Cámara de los Estados. Lo que resulta especialmente cierto en relación con las relaciones internacionales. En efecto, a nadie puede ocultársele que cuando el art. II, sección $2 .^{a}$. 2 de la Constitución establece que el Presidente «Tendrá facultad, con el consejo y consentimiento del Senado, para firmar tratados con la conformidad de dos tercios de los senadores presentes y, designará y, con el consejo y consentimiento del Senado, elegirá a los embajadores, a otros ministros públicos y cónsules, a los magistrados de la Corte Suprema y a todos los demás funcionarios de los Estados Unidos para cuya elección no se prevé aquí otra forma distinta, y que hayan sido establecidos por ley», lo que el Constituyente hizo fue, de una u otra suerte, el reproducir lo dispuesto en los Artículos de la Confederación y Unión Perpetua sobre los poderes que correspondían al viejo Congress cuando los Estados Unidos actuaban como una Unión de Derecho International. Quedando, como no podría ser de otra manera, exceptuadas de ello las facultades que correspondían en la etapa federal a los Poderes Ejecutivo (el Presidente) y Judicial, que, en todo caso, y respondiendo a la lógica propia e inherente al Estado Constitucional, habían sido creados por el poder soberano y podrían tan sólo actuar en el marco de competencias que éste, en cuanto que poder anterior y superior a ellos, les atribuyó.

Ocurre, sin embargo, que el carácter de auténtico residuo contractualístico del Senado se hace muchísimo más evidente en cuanto a la composición de esta nueva Cámara del Congreso federal. De una manera muy concreta, en cuanto a lo que se presenta como el rasgo más característico de este modelo de Cámara de los Estados. Nos referimos, innecesario debiera ser aclararlo, a la exigencia del voto igual.

Lo de menos sería el detenernos a exponer las consecuencias que este principio tiene para el supuesto de una hipotética modificación formal del art. I, sección $3{ }^{a} .1$ del Texto de 1787. Sobre todo, en orden a determinar si la actuación de ese hipotético poder de reforma podría, o no, ser considerada como una operación jurídica válida, lícita y legítima. Tanto más cuanto que ya tuvimos ocasión de señalar, siguiendo las enseñanzas de Bryce, Burgess, Esposito y De Vega, que, porque, de acuerdo con lo que se desprende del inciso final del propio art. V, la eliminación de la igualdad de voto de los Estados sólo sería posible y viable cuando la misma fuese aprobada por unanimidad, nos encontramos con que ésta es una materia que, si bien no de iure, si de facto, termina por quedar fuera de las posibilidades de actuación del poder de revisión. De ahí se deriva que Le Fur haya afirmado que el principio de la igualdad de voto en el Senado fue, de una u otra suerte, ya excluido por los Founding Fathers de las materias sobre las que podía decidir lícita, válida y legítimamente el poder de reforma.

Lo que nos interesa es que lo que los Founding Fathers hicieron fue hacerse eco del principio fundamental sobre el que se había edificado la preexistente Confe- 
deración: que la vida y el gobierno de la Confederación y Unión Perpetua debía desarrollarse de acuerdo con la lógica que se deriva del principio y de las ideas democráticas. De esta suerte, nos encontramos con que esta última, a pesar del hecho de constituir un inequívoco modelo de lo que Le Fur denominaba «système d'Ètats», se había construido con la finalidad de hacer reales y efectivas las ideas de Democracia, Libertad e Igualdad. E importa advertir, en este sentido, que si los autores de los Articles se preocuparon de que esta última idea adquiriese auténtica entidad y realidad en relación con los ciudadanos de las colectividades confederadas, y para un tal fin consagraron la igualdad de los habitantes de cada Estado en el art. $4 .^{\circ}$ de aquel cuerpo normativo, lo hicieron también para establecer un mismo status jurídico y político entre todas las Comunidades Políticas que integraban la Staatenbund estadounidense. Esto es, en todo caso, lo que pretendieron materializar en el art. 5. ${ }^{\circ}$ de los Artículos de la Confederación y Unión Perpetua.

En efecto, partiendo de la loable intención de hacer reales y efectivas las ideas de Democracia, Libertad e Igualdad, y habiendo elevado a esta última en el componente básico de las relaciones entre los miembros, obligado resultaba que, en este último precepto, los delegados estatales estableciesen que «Ningún Estado quedará representado en el Congreso por un número inferior a dos miembros, ni por un número superior a siete; [...]. [...] Cada Estado mantendrá sus propios delegados en la reunión de los Estados y mientras actúen como miembros del Comité de los Estados. [...] Para la adopción en el Congreso de decisiones relativas a los Estados Unidos cada Estado tendrá un solo voto». Las concomitancias existentes entre este texto y la solución articulada por los Founding Fathers en 1787 son, indiscutiblemente, evidentes. Lo que nos exime de continuar haciendo más consideraciones al respecto.

\section{La inequívoca inspiración confederantista del Bundesratb guillermino}

Si la posibilidad de calificar el Senado estadounidense como un manifiesto ejemplo de esos «Residui contrattualistici» de los que hablaba La Pergola es manifiesta, debemos indicar que la influencia de los esquemas del confederantismo resulta, a nuestro juicio, todavía mucho más evidente en el supuesto alemán. Y, de una manera muy particular, en el que constituyó el primer Estado Políticamente Descentralizado alemán: el Imperio guillermino.

Admitir lo correcto de la anterior consideración no ha de ser muy difícil de lograr. No lo será, en todo caso, para todos aquellos constitucionalistas que acepten que tenían toda la razón aquellos grandes Maestros, - como, de manera indiscutible, lo eran y lo son, Jellinek, Schmidt, Smend, Heller, Hesse, La Pergola y De Vega-, cuando afirmaban que sólo sería posible alcanzar un ponderado y cabal conocimiento y comprensión de las Ciencias Constitucionales cuando, tratando de dar cumplimiento a la idea de que la misión prioritaria de la Teoría del 
Derecho Constitucional es la de proceder a la explicación de la normativa fundamental vigente en una determinada Comunidad Política, así como de los distintos proyectos elaborados por los prácticos de la política para su posible desarrollo y reforma, que, a la postre, facilite tanto a los ciudadanos de a pie, como al resto de los profesionales del Derecho y, con una particular y singular importancia, y como ya sentó, en 1800 Fichte, a todos aquéllos que ocupan algún cargo público y que, precisamente por esta condición, son los que crean la realidad jurídica y política que al Staatsrechtlehrer le cumple estudiar, una comprensión global del Derecho Constitucional, formal y material, vigente en el Estado, cuando el constitucionalista, tiene en consideración, y tiene muy presentes, todas las circunstancias sociales, económicas, políticas e históricas que determinaron que un concreto y específico Texto Constitucional fuese aprobado en los términos, y con los contenidos, con que lo fue y no con otras soluciones radicalmente diversas y contrarias.

Lo de menos sería detenernos a aclarar que lo anterior no es más ni menos que el afirmar que el único modo posible de actuar en el nivel de la normativa fundamental del Estado es la de tener en cuenta aquellas fundamentales categorías de «espacio» $\mathrm{y}$ «tiempo» que, pese a todas las objeciones realizadas al respecto por Kelsen ${ }^{8}$, fueron, como nos recordaba hace ya algunos años el Maestro De Vega, brillante, feliz y afortunadamente recuperadas por Heller y Smend para el estudio cabal del Derecho Constitucional por el que se rige, en el momento que sea, la vida de un determinado y concreto Cuerpo Político. Y ello, a pesar de que en España esta máxima parece haber sido olvidada desde los últimos años de la pasada centuria por un buen número de los miembros de la clase política y, lo que es todavía más grave, por no pocos integrantes de la clase académica.

Lo que interesa es sólo poner de manifiesto que quien así actúe no tendrá ningún problema para comprender que el Bundesrath diseñado en 1871 es un fiel reflejo de las especiales y particulares circunstancias que concurrieron en el proceso histórico de formación del Estado alemán, así como que su regulación concreta, tanto en lo que se refiere a sus atribuciones como a su composición, es claramente tributaria de la solución adoptada en la vieja deutscher Bund. De esta suerte, nos encontramos con que cualquier constitucionalista ha de estar en condiciones de comprender que esta influencia a la que aludimos no es sólo la consecuencia de que fueran no pocos los juristas alemanes que, partiendo de la antidemocrática, y radicalmente contraria a la lógica intrínseca del «Estado Constitucional», idea del foedus, mantuvieron la tesis de que la deutscher Bund, a pesar de que se trataba de una muy rudimentaria Confederación que, además, incorporaba todavía muchas soluciones propias del feudalismo (O. Bühler), constituía el modelo paradigmático, y, según ellos, el único modo posible de organizar adecuadamente una Unión de Derecho Constitucional, de la forma política «Estado Fede-

8 Cfr. H. Kelsen, El Estado como integración. Una controversia de principio (1930), Madrid, 1997. 
ral». Junto a esta causa, está el principio que actuó como único y exclusivo criterio inspirador, fundamentador, vertebrador y articulador de aquel documento de gobierno que, hijo de las concepciones del monarquismo constitucional, trataba de conducir la vida de la nueva Comunidad Política única alemana. Y no puede olvidarse que fue, como nos enseñó Heller, en el marco de la Confederación germánica donde se definió, tanto a nivel conceptual como a nivel normativo, el principio monárquico como, al decir de Treitschke, contenido medular y basilar del nuevo Derecho Político Constitucional alemán. Lo hizo ya, y a instancias del rey de Wüttemberg, en el art. 13 del llamado Acta Federal de 8 de junio de 1815, y lo precisaría todavía más el art. 57 del Acta final o Protocolo adicional de Viena de 1820, a cuyo tenor «Todo el poder del Estado tendrá que estar concentrado en el Jefe Supremo del mismo, y el Soberano, por medio de una Constitución estamental, podrá estar ligado tan sólo en el ejercicio de determinados derechos a la colaboración de los Estamentos». Lo que habría de resultar especialmente interesante para quienes, como sucedía con los autores de la Constitución de 1871, no tenían otra pretensión que la de articular un sistema jurídico y político que permitiese erigir al rey de Prusia en la posición de único soberano posible en el Estado, aparentando, no obstante, respetar las viejas «libertades de los territorios» para, con ello, asegurarse la obediencia y sometimiento de los Junkers a la voluntad del rey de Prusia/Emperador de Alemania. Circunstancia de la que, aunque muchas veces se ignora, de manera particular por parte de las fuerzas integradas en el catalanismo romántico, espiritual, irracional, mítico y místico, determinó que la vida del Imperio guillermino se definiera realmente, y como nos dice Triepel $^{9}$, por su más que sobresaliente tendencia hacia la centralización del Estado Federal regido, por lo menos formalmente, por el Texto de 1871.

Sea de ello que sea, interesa resaltar la influencia de la Historia en el nacimiento del Bundesrath guillermino. Peso de la Historia que en modo alguno es pequeña. Y que se hace especialmente patente en lo que se refiere a las funciones jurisdiccionales que el Constituyente de 1871 atribuyó al Consejo Federal. Problemática a la que no podríamos dejar de referirnos, siquiera sea de manera sucinta. Y, en este sentido, nos contentaremos, y aunque la cita sea larga, con transcribir lo que señaló Le Fur a este respecto: «Toutes les Constitutions fédératives modernes possèdent à côté des autorités législatives et exécutives, un Tribunal fédéral suprème. La Constitution allemande de 1871 n'en avait établi aucun. La pression des circonstances a forcé en 1877 à en créer, [....; mais malgré cette création, le Bundesrat a conservé les importantes attributions judiciaires qui lui avaient été confiées, de sorte que le tribunal de l'Empire (das Reichsgericht), n'a encore qu'une compétence très limitée, surtout en matière politique».

Hacerlo de este modo tiene un sentido pleno. Desde luego, lo tiene para alcanzar una comprensión adecuada que permita obtener una solución precisa al

9 Cfr. H. Triepel, Unitarismus und Föderalismus in Deutschen Reiche, Tubinga, 1907. 
interrogante que da origen a este trabajo. Pero no es sólo esto. Existe otro motivo, y que no ha de ser muy difícil de comprender. Logrando, de esta suerte, justificar nuestra afirmación de que la posibilidad de considerar a la Cámara de los Estados como un supuesto inequívoco de esos residuos contractualistas, o confederantistas, se hace todavía mucho más patente en el Derecho Constitucional alemán. Lo que se comprende con sólo tomar en consideración que la regulación concreta realizada en 1871 de este órgano no hace más que confirmar las grandes tensiones territoriales que existieron a lo largo de todo el proceso histórico de formación del Estado alemán. Circunstancias históricas que fueron bien distintas a las que concurrieron en el proceso histórico de formación de los Estados Unidos de América como Estado Federal.

Y es que no puede olvidarse, en este sentido, que frente a la idea de la igualdad que había presidido la vida de la Confederación y Unión Perpetua de los Estados Unidos de América, y que fue uno de los principales condicionantes para que la Constitución de 1787 fuera aprobado como lo fue, incluyendo el principio de igualdad de voto en el Senado, algo muy distinto, por no decir absolutamente contrario, fue lo que caracterizó el proceso histórico de creación del Estado alemán. Éste, efecto, - y como venía ya planteándose desde el ámbito científico e intelectual, en donde, si Hegel ya había apuntado la posibilidad de que la unión estatal alemana podría tomar como base la elección entre Prusia y Austria como potencia preponderante y, en consecuencia, fundamento de la unidad, Fichte, por su parte, se decantaba abiertamente porque fuera una Prusia articulada según los esquemas de Stein-Hardenberg la que sirviera de base para la constitución de la República unitaria-, se desarrollaría como una auténtica pugna entre los territorios, singularmente entre Austria, Prusia y Baviera, por alcanzar una posición y situación de hegemonía y privilegio respecto del resto de los Länder que integraban la Confederación germánica. Lo que hubo de reflejarse en la normativa fundamental de la deutscher Bund, y, como decimos, terminaría por influir en el Derecho Constitucional del Estado que substituyó a aquélla. Lo hizo, y de un modo incuestionable y que, en todo caso, resulta difícilmente discutible, en la solución concreta adoptada sobre la Cámara de los Estados por el documento de gobierno de la monarquía constitucional de 1871.

Al igual que la estadounidense Confederación y Unión Perpetua, nació la deutscher Bund configurada, y a pesar de todas las singularidades que la misma revestía, como una auténtica Unión de Derecho International. Lo que, traducido en otros términos, significaba que los sujetos de la misma lo eran los Estados soberanos que habían sido identificados en el art. 6. ${ }^{\circ}$ del Acta Federal de 1815. Asimismo, nos encontramos con que, al igual que lo que sucedía en el, por decirlo en la terminología de Le Fur, el «système d'États» estadounidense, la Confederación germánica contaba con un único órgano común y permanente. En efecto, podríamos decir que el viejo Congreso confederal estadounidense encontraba, de alguna manera, su correlato en la Bundesversammlung. Órgano que era en realidad un verdadero Congreso de diplomáticos enviados por los 
Gobiernos de los distintos Estados soberanos para debatir y salvaguardar sus respectivos intereses.

Se creaba, de este modo, un órgano decisorio único para la Unión de Derecho International. Sus funciones se correspondían, desde un punto de vista general, con las que suelen ser las propias de este tipo de órganos en estas formas de organización jurídica y política de los Estados soberanos. En efecto, a la Bundesversammlung le correspondía emanar todas las decisiones que afectaban a la propia Confederación, y tanto de carácter ejecutivo como legislativo, quedando tan sólo excluida de esta facultad, y aun así de modo relativo, en tanto en cuanto que el órgano encargado de solucionar esto era un comité cuyos miembros eran designados por la propia Dieta Federal y entre sus miembros, la resolución de los posibles conflictos que pudieran surgir entre las colectividades particulares confederadas entre sí, lo que se hacía a través de la figura del arbitraje, la llamada Austragalinstanz, y no como consecuencia de las facultades jurisdiccionales de las que, aunque ciertamente limitadas, disponía, de acuerdo con la normativa fundamental confederal, la Bundesversammlung.

No podríamos, sin embargo, dejar de consignar que, de un modo muy distinto a lo que constituía la regla general en el Derecho comparado, tenía la Dieta Federal de la deutscher Bund una serie de competencias en relación con la facultad normativa de las colectividades confederadas, cuya importancia y trascendencia en modo alguno eran pequeñas pero, además, ocurre que las mismas fueron, de una u otra forma, incorporadas a la Constitución guillermina y, atribuidas al haz de actuación del Bundesrath. Resultado de lo cual fue que en el primer Estado alemán era un órgano que, con total independencia de si se considera que el mismo forma parte del Parlamento federal o no, tenía, en cuanto a sus funciones generales, un carácter legislativo, y no los tribunales de justicia, el encargado de atender ese requisito fundamental para la posible atribución de la naturaleza federal a una determinada estructura estatal de que necesariamente ha de existir un órgano encargado tanto de llevar a cabo el control de constitucionalidad como la jurisdicción para la resolución de los posibles conflictos que pudieran existir entre los miembros con la organización política central o entre sí, como mecanismo jurídico idóneo para garantizar la existencia y subsistencia futura tanto de la Federación como la de los distintos centros autónomos de decisión política democrática y legítima.

Nos referimos, a que correspondía a la Dieta Federal, de manera más concreta a la engere Versammlung, no sólo la competencia exclusiva sobre la interpretación definitiva de la normativa fundamental por la que se regía la Confederación germánica, así como la de no sólo asegurar la vigencia efectiva de ésta, sino también, y con igual importancia, la de fiscalizar que los Legisladores de las comunidades confederadas respetaban el contenido material de aquéllas en tanto que normas jurídicas obligatorias y vinculantes para sus destinatarios, en este caso las autoridades de los Estados soberanos que integraban la deutscher Bund. E importa, en este sentido, advertir que la competencia general atribuida a la Dieta Federal de 
llevar a cabo la interpretación definitiva de la normativa fundamental de la Confederación germánica, así como la de asegurar su carácter de norma jurídica obligatoria y vinculante, a lo que condujo fue a que la Bundesversammlung quedase investida, sino de iure, sí al menos de facto, como un órgano facultado para proceder a enjuiciar la validez, licitud y legitimidad tanto de Códigos Constitucionales que pudiesen aprobar los Estados confederados una vez que el Acta Federal y el Protocolo adicional habían entrado en vigor, así como la de cualquier reforma que las autoridades de las colectividades particulares pudiesen llevar a cabo en sus respectivos Textos, y con independencia de si los mismos se encontraban ya en vigor antes de la puesta en marcha de la Unión de Derecho International, o si, por el contrario, habían sido aprobados después de la creación de la deutscher Bund.

Ocurre, de cualquiera de los modos, que la decisiva influencia que tuvo el conflicto entre los territorios por hacerse con la hegemonía dentro de la organización estatal resulta todavía mucho más evidente en cuanto a la composición de la Dieta Federal. En este sentido, no puede olvidarse que nació la deutscher Bund disfrutando, como venía haciéndolo en el contexto de la Rheinbund, Austria de una situación de patente privilegio respecto del resto de los Estados en aquélla. Circunstancia que se manifestaba, en primer lugar, en el hecho de que tanto el Acta Federal como el Protocolo adicional estableciesen, de forma expresa, que la presidencia de la Bundesversammlung le correspondería de manera perpetua al Emperador austriaco. Con lo que, de uno u otro modo, éste acababa por presentarse como el auténtico Presidente de la Confederación germánica. En segundo término, en que el Emperador austriaco, en tanto que titular del Poder Ejecutivo de Austria y, por ello mismo, encargado de designar a los diplomáticos que actuaban y decidían en ésta, contaba con un mayor número de votos.

Ahora bien, es menester advertir, y de manera inmediata, que este status de potencia hegemónica del que disfrutaba el Emperador de Austria no fue pacíficamente admitido por todos los demás Estados confederados. En particular, se opondría a ello, como venía haciéndolo ya, y a instancias de Napoleón, desde la época de la Confederación del Rin, el rey de Prusia. Y debemos, asimismo, señalar que finalmente lograría este último hacerse con la hegemonía en la Confederación germánica, en claro detrimento de una Austria que, por esta misma circunstancia, y no sin presentar una gran oposición - para lo cual, entre otras cosas, el Emperador de Austria animó al rey de Baviera a reivindicar su Estado soberano como posible beneficiario de los privilegios que se derivarían de su posible conversión en Presidente de la deutscher Bund-, acabaría por abandonar la organización confederal, con la firma del Tratado de Praga de 23 de agosto de 1866.

No puede ningún jurista dejar de constatar que el cambio en la posición privilegiada logrado por el rey de Prusia, que, habiendo tenido un origen fáctico terminaría, lógicamente, siendo recogido por el Derecho, se debió a una de estas causas extrajurídicas de las que, como afirmó Schmidt, jamás puede prescindir el profesional de las Ciencias Jurídicas para lograr alcanzar una cabal y ponderada comprensión de las normas jurídicas, ya sean históricas, ya del Derecho vigente, 
que pretende estudiar y explicar. En concreto, el éxito de la pretensión del rey de Prusia se debió a causas de tipo económico. En efecto, fue la puesta en marcha en 1818 de la Zollverein, en la que Prusia, que había sido su promotora, ocupaba una posición central como consecuencia de su situación geopolítica, y a la que terminaron uniéndose todos los Estados integrados en la Confederación germánica salvo Austria, lo que hizo que el rey de Prusia lograse reunir en 1848 los votos necesarios para ser nombrado, en substitución del Emperador austriaco, como Presidente perpetuo de la Bundesversammlung, así como el que se le atribuyesen a él el mayor número de votos en el seno de la Dieta Federal. Y esto fue, en definitiva, lo que se consignó, de manera expresa y formal, en el texto de la aprobada, aunque sin que la misma, como sabemos, llegase a entrar en vigor, Franckfurter Reichsverfassung. Texto éste que no expulsaba formalmente a Austria de la deutscher Bund, pero que determinaba que, al quedar equiparada al resto de los Länder, y condenarla a jugar un papel secundario después de tantos años de haber disfrutado de la posición de potencia hegemónica, se viese forzada fácticamente a abandonar la Unión de Derecho International.

Hecho éste que, por lo demás, y en la medida en que venía a poner fin a la existencia de la Confederación germánica, implicó también el cese de la pugna por la hegemonía entre Prusia y Baviera. Lo que no ha de ser muy difícil de comprender. Al fin y al cabo, lo que sucedía es que la conclusión del citado Tratado de Praga de 23 de agosto de 1866 supuso, de una u otra suerte, la disolución de la propia Confederación germánica. Ésta, en efecto, debía ser substituida por dos nuevas y, aunque relacionadas como consecuencia de los pactos por los que se establecía entre ellas una mera alianza internacional, y en el plano económico a través de la permanencia de todos los entes confederados en la Zollverein, independientes Uniones de Derecho International: la Norddeutscher Bund, - a la que no ha faltado algún autor que, como, p. ej., Bühler, ha concedido ya la naturaleza de ser un auténtico Estado desde la entrada en vigor de la llamada Constitución federal de 1867; con lo que, de una u otra suerte viene a aceptar las tesis de los Meyer, Haenel y Le Fur, conforme a las cuales el nacimiento del Estado Federal puede producirse jurídicamente y como consecuencia de la celebración de un previo Tratado Internacional-, y la Confederación de la Alemania del Sur. De esta suerte, las tensiones existentes entre el rey de Prusia y el rey de Baviera llegaban, como decíamos, a su fin. Y ello, por la sencilla razón de que si la Confederación de la Alemania del Norte se formaba alrededor de Prusia y, además, todas las colectividades integrantes reconocían la posición preponderante que en el nuevo ente interestatal iba a ocupar Prusia, Baviera, por su parte, estaba llamada a capitanear la vida de la prevista, pero nunca constituida, Unión de Estados de Derecho International de la Alemania del Sur.

Sea de ello lo que sea, lo que nos interesa es que esta situación fáctica, y bajo la influencia de las soluciones normativas adoptadas tanto en la deutscher Bund, como en la «Constitución federal» de la Norddeutscher Bund, sería la que se reflejaría en la Constitución de 16 de abril de 1871, con la que, ahora de modo indis- 
cutible, Alemania se constituía en un Estado único. Lo que queda demostrado con la simple lectura de la regulación de este Código Constitucional hizo tanto de la figura del Emperador, al que oficialmente, y algunos iuspublicistas llegaron a aceptarlo de un modo más que donoso ( $v . g r$. P. Laband), se le denominaba Presidente de la Federación, y del Bundesrath. Quien así lo haga, no tendrá dificultad alguna para descubrir que lo que subyace en esta regulación es la vieja pugna por el status de potencia hegemónica, preponderante y privilegiada que habían venido manteniendo el rey de Prusia y el rey de Baviera. Como también ha de serle de fácil deducir que, aunque reconociendo ciertamente algunos privilegios a Baviera, la Constitución guillermina, de conformidad con la orientación que von Bismarck había imprimido al proceso de unificación de Alemania, favorecía notablemente la posición del rey de Prusia.

Lo anterior resulta indiscutible en lo que hace a la figura del Kaiser. Tanto es así, que se reconocía constitucionalmente como Emperador de Alemania a aquél que ostentase el título de rey de Prusia. A ello se refiere, de manera expresa, el art. 11.1 del Texto de 1871. La importancia de este precepto, en todo caso, fue puesta de manifiesto, en el tomo $2{ }^{\circ}$ de sus célebres «Studien zum deutschen Staatsrechte», por Albert Haenel ${ }^{10}$. Y lo hizo, de una manera muy concreta, cuando escribió que «La transformación de la presidencia prusiana del Proyecto de Constitución en el poder imperial de la Constitución del Imperio divide en dos partes las atribuciones que el Proyecto había concentrado en las manos de Prusia. Aunque el Poder Ejecutivo y las prerrogativas de la corona débilmente organizadas han pasado al poder imperial, todas aquellas atribuciones del poder presidencial que representaban la influencia del Poder Ejecutivo sobre el Poder Legislativo, por el derecho de iniciativa, el derecho de voto, el veto en el Bundesrath, la representación en el Reichstag, han permanecido como por el contrario, en las manos de Prusia considerada como Estado particular». No puede olvidarse, además, que las ya muy importantes atribuciones en materia legislativa federal que le habían sido atribuidas al rey de Prusia por el documento de gobierno de 16 de abril de 1871, se vieron notablemente incrementadas por la aprobación de la ley de 9 de junio de 1871, que además le atribuía el ejercicio de la soberanía en la llamada Reichsland (la Alsacia-Lorena). Lo que, en último extremo, resultaba posible por la lógica interna inherente a la monarquía constitucional. Téngase en cuenta, a este respecto, que, porque eran las ideas y el principio monárquico el que actuaba como criterio inspirador, vertebrador, fundamentador y articulador del sistema, en modo alguno se derivaba la nulidad, y además ex tunc y ex nunc, de cualquier norma ordinaria que contuviese soluciones contrarias a las establecidas por la propia Constitución, siempre y cuando, y como condición indispensable, lo establecido por la norma de rango inferior favoreciese los intereses del rey de Prusia/

10 Cfr. A. Haenel, Studien zum deutschen Staatsrechte. II. Die organisatorische Entwicklung der Reichsverfassung, Leipzig, 1880. 
Emperador de Alemania, en el sentido de que, de conformidad con los esquemas con los que operaba el monarquismo constitucional, lo que sucedía es que, como escribió Laband ${ }^{11}$, «La afirmación de que las leyes ordinarias deben estar siempre en armonía con la Constitución y no resultar incompatibles con ésta, constituye simplemente un postulado de práctica legislativa, pero no un axioma jurídico. Aunque resulte deseable que el sistema de Derecho Público y Privado [es decir, entre la Constitución y la legislación ordinaria, que es fruto de la actuación de un Parlamento supeditado a la voluntad soberana del monarca] no aparezca en contradicción con el acto constitucional, la existencia de una contradicción entre ambos es posible de hecho y admisible en Derecho».

De cualquier modo, la influencia de la pugna entre el rey de Prusia y el rey de Baviera por la hegemonía se hace notar todavía más en cuanto a la composición del nuevo Consejo Federal. Y lo hace, precisamente, por el dato incontrovertido de que el reparto de los escaños en el Bundesrath favorecía notablemente los intereses de éstos frente a los demás señores territoriales, y de una manera muy particular los del rey de Prusia. Basta, en este sentido, con tomar en consideración que lejos de corregirlos desequilibrios que en la Bundesversammlung existían, lo que la Constitución de 1871 hacia era consolidarlos y profundizarlos. Téngase en cuenta que, de acuerdo con lo establecido en el art. $6 .^{\circ}$ de este Texto, a Prusia, además de la Presidencia del Consejo Federal — lo que otorgaba al rey de Prusia un grandísimo poder, en la medida en que el Presidente del Bundesrath, que correspondía al Reichskanzler, que era nombrado propio rey de Prusia, le correspondía, ex arts. 5. ${ }^{\circ}, 37$ y 78 , un voto de calidad en la aprobación de las normas jurídicas siempre que hubiese un empate entre los representantes de los Gobiernos de los Estados-, le correspondían 17 votos. El número de 17, interesa recordarlo, aparece ya en la llamada Constitución de la Confederación de la Norddeutscher Bund. Por su parte, y como reflejo de su condición de segunda potencia preponderante, a Baviera se le otorgaban 6 . El resto de los votos se distribuían del siguiente modo: 4 para Saxe y Württemberg; 3 para Baden y Hesse; 2 para Brunswick y Mecklembourg-Schewerin, y 1 para cada uno de los restantes 17 Länder. Singular situación tuvo a este respecto el territorio de Alsacia y Lorena. Téngase en cuenta, en este sentido, que el Texto Constitucional no reconocía ningún voto a éste. Ahora bien, no puede olvidarse que en un primer momento, y mediante una ley de 1879, se admitió en el Derecho guillermino que el territorio de Alsacia y Lorena podría proceder, aunque careciendo todavía de votos, a la defensa de sus intereses en el Consejo Federal. Lo que se perfeccionaría todavía más en 1911 cuando, a través de la revisión de la Constitución de 1871, le fueron adjudicados 3 votos a Alsacia y Lorena.

Las consecuencias derivadas de este reparto de votos en el Bundesrath, jamás podrían considerarse como algo irrelevante. Antes al contrario, nos encontramos

11 Cfr. P. Laband, Le Droit Public de l'Empire Allemand, París, 1901, t. II. 
con que tenía una importancia y trascendencia capital para el funcionamiento mismo del propio Estado cuya vida pretendía regular y conducir la Constitución de 1871. Lo que se hace particularmente cierto en relación con lo que, de manera casi unánime, los cultivadores de las Ciencias del Derecho del Estado, y desde las más diversas posiciones metodológicas y entendimientos políticos de la cuestión, han considerado el contenido central de toda ordenación jurídica de las estructuras estatales que se corresponden con el concepto de Unión de Derecho Constitucional. Nos referimos, como es obvio, a la problemática del ejercicio de esa facultad constitucional que la dogmática alemana bautizó con el nombre de Kompetenz-Kompetenz.

No puede olvidarse que fue el criterio unánime en la Teoría Constitucional del Estado Federal el de que, en la medida en que las competencias que habrían de corresponder inicialmente tanto a la organización política central como a las organizaciones políticas regionales habían sido consignadas por la voluntad soberana del Pouvoir Constituant federal, la única manera, en principio, posible de que el primigenio ámbito competencial pueda ser alterado válida, lícita y legítimamente es la de que el ejercicio de la competencia sobre la competencia, además de tener que respetar la existencia de unos límites materiales absolutos aunque sean implícitos, ha de encontrarse limitado también desde el punto de vista formal. Lo que significa que cualquier ampliación del ámbito competencial de la organización política central o de los distintos centros autónomos de decisión política democrática y legítima podrá únicamente llevarse a cabo con una rígida y escrupulosa observancia del procedimiento establecido para llevar a cabo las revisiones del propio Texto federal.

Y este principio es el que se veía notablemente afectado por el reparto de votos en el Bundesrath efectuado por el Constituyente de 1871. Y lo hizo, en todo caso, otorgándole al rey de Prusia un poder colosal sobre la decisión final en el supuesto de que se plantease una reforma que tuviera por objeto el ejercicio de la Kompetenz-Kompetenz. Tanto, que en modo alguno resulta exagerado afirmar que, muy en contra de lo que sostuvieron, entre otros, Laband, Brie y Rosin ${ }^{12}$, lo que la normativa fundamental del primer Estado Políticamente Descentralizado alemán hacía era erigir al rey de Prusia como el único titular tanto de la soberanía como del ejercicio de la soberanía en el marco del Imperio alemán.

Lo de menos, como es evidente, sería detenerse a indicar que lo que el Constituyente de 1871 hizo fue, única y exclusivamente, repetir lo dispuesto en la Constitución de 1867. Solución que, como a nadie puede ocultársele, convertía a la Norddeutscher Bund en una de las pocas excepciones habidas en el ámbito del Derecho positivo en cuanto al cómo podría llevarse a término la reforma de la normativa fundamental en las Uniones de Derecho Internacional. En efecto, frente al principio de que, como mecanismo adecuado para proceder a la salvaguardia

12 Cfr. S. BRIE, Der Bundesstaat: Eine historich-dogmatische Untersunchung, Leipzig, 1884. 
de la soberanía que corresponde a los Pueblos de las distintas Comunidades Políticas confederadas (A. La Pergola, P. De Vega, etc.), la reforma del instrumento de gobierno por el que se rige la Confederación de Estados sólo podrá aprobarse por el voto unánime de los Estados soberanos que la integran, se estableció en la última Staatenbund alemana el que el Texto fundamental podría, — salvo en el caso de los iura singularia de los que disponían algunos de los Estados, cuya supresión, en la medida en que requería el consentimiento de los mismos, tan sólo podría realizarse por unanimidad, de suerte tal que, como sucedía con el voto igual en el Senado estadounidense, terminaban convirtiéndose de hecho, y como reconoció ya Laband, en una materia intangible-, ser aprobada de acuerdo con el principio de la mayoría cualificada, aunque, eso sí, y como nos dicen Le Fur y Durand, la regulación se hizo ya en la Confederación de la Alemania del Norte de manera tal que se asegura se la posición hegemónica de Prusia en la Norddeutscher Bund. Lo que, en todo caso, se derivaban del hecho de que Prusia tenía conferidos 17 de los 45 sufragios posibles en la Cámara de los Estados y que esto suponía que contaba con una más que los que eran necesarios para imposibilitar la realización del cambio formal del cuerpo normativo por el que se regía la Unión de Derecho International de la Alemania del Norte.

Lo que en realidad nos interesa es poner de manifiesto que, al haber consagrado el procedimiento de reforma establecido ya en la «Constitución» de 1867, lo que sucedía no podía ser, en verdad, más simple. El rey de Prusia, sino de iure, si al menos de facto, quedaba convertido en el dueño y señor de la Kompetenz-Kompetenz. Es más, en rigor lo que el art. 78 del Texto guillermino hacía era, pura y simplemente, consagrar definitivamente la soberanía del Kaiser. Lo que, ni que decir tiene, suponía destruir tanto la lógica interna de la forma política general «Estado Constitucional», que se basa en la idea de que en su seno no puede existir otras soberanía que la de la Constitución y el Derecho (H. Krabbe, H. Kelsen), como la del «Estado Políticamente Descentralizado», en donde, como advirtió Friedrich y, de algún modo, admitió nuestro Tribunal Constitucional, el único soberano posible es el Poder Constituyente que aprobó la Constitución federal. Aunque, sin duda, debemos hacer alguna consideración al respecto.

El problema se hace meridiano cuando se pone en relación lo establecido en este art. 78 con la distribución de los votos en el Bundesrath. Téngase en cuenta, a este respecto, que el art. 78 establecía, de manera expresa, que no podría aprobarse ninguna reforma constitucional si se oponían a ella en el Consejo Federal 14 votos. Decisión que pudiera interpretarse, y ciertamente no ha faltado quien así lo ha hecho (p. ej., J. W. Burgess, J. A. R. Marriot, K. Loewenstein, G. de Vergottini $\left.{ }^{13}\right)$, que el Constituyente de 1871 estaba reconociendo a todos los Länder un cierto derecho de veto frente a una hipotética modificación formal del Texto

13 Cfr. J. A. R. Marriot, The mechanism of the Modern State. A treatise on the Science and Art of Government, Oxford, 1927, vol. I; G. DE VergotTini, Derecho Constitucional Comparado, Madrid, 1983. 
Constitucional. Ahora bien, lo que no puede perderse de vista es que, teniendo en cuenta el art. $6 .^{\circ}$, la única posibilidad que tenían los demás centros autónomos de decisión política de ejercitar este veto era el de proceder a ponerse de acuerdo los unos con los otros. Y es que, en efecto, sólo así podrían éstos reunir esos 14 votos necesarios para impedir la definitiva, válida, lícita y legítima aprobación del proyecto de reforma de que se tratase. Sin embargo, ocurre que como muy bien comprendió Laband — que, de este modo, venía a refutar su propia tesis de que en la Alemania de 1871 la soberanía correspondería por igual al Emperador y a los gobernantes de los centros autónomos de decisión política-, lo que verdaderamente establecía el art. 78 era un derecho de veto efectivo en favor del rey de Prusia. Y ello, por la muy simple razón de que, al contar éste con 17 votos en el Bundesrath, lo que acababa sucediendo es que ni el voto unánime en el Reichstag, ni, asimismo, la voluntad común de los otros Länder favorables a la revisión, podrían nunca imponer una reforma constitucional con la que no estuviese de acuerdo el rey de Prusia. Se comprende, sin dificultad alguna, el por qué los académicos identificaron, de manera unánime, el art. 78 de la Constitución guillermina con el término de «cláusula prusiana».

\section{CONCLUSIONES PROVISIONALES: LA DIFÍCIL TAREA DE CONJUGAR LA POSIBLE SUPRESIÓN DEL SENADO CON LA NECESARIA PARTICIPACIÓN DE LAS COMUNIDADES AUTÓNOMAS EN EL PROCESO DE TOMA DE DECISIONES POLÍTICAS FUNDAMENTALES EN EL ESTADO POLIITICAMENTE DESCENTRALIZADO}

Realizado el estudio anterior, es cuando nos encontramos, de manera efectiva, en condiciones de llevar a cabo aquella tarea que, en cuanto que constitucionalistas, nos corresponde en orden a contribuir a la feliz evolución de la realidad jurídica y política del Estado: la de proporcionar a los que verdaderamente crean esa realidad jurídica y política, gobernantes y gobernados, todos los conocimientos necesarios para qué puedan tomar una decisión cabal y ponderada a la hora de proceder a la reforma de determinadas instituciones. Y, además, podemos hacerlo de acuerdo con aquel esencial criterio marcado por ese gran jurista conservador que fue Triepel ${ }^{14}$ para que, ante el hecho innegable de que, por el mero desarrollo correcto de la propia lógica del comportamiento científico, en el marco de las Ciencias Sociales - entre las que, como ciencias social-normativas, se encuentran las Ciencias Jurídicas, y de un modo especialmente singular la Teoría del Derecho Constitucional (K. Stern, H.-P. Schneider)—, toda toma de posición intelec-

14 Cfr. H. Triepel, Derecho Público y Política (Discurso de toma de posesión del Rectorado de la Universidad Federico Guillermo de Berlín el 15 de octubre de 1926) (1927), Madrid, 1974. 
tual acaba traduciéndose, como con acierto advirtió De Vega ${ }^{15}$, en una toma de posición política, los escritos elaborados por los profesionales universitarios del Derecho puedan ser comprendidos como unos auténticos trabajos científicos, con los que se puede estar de acuerdo o, por el contrario, discrepar de las conclusiones, y no, y al modo descrito por Mannheim ${ }^{16}$, descalificados con, en el mejor de los casos, el falaz argumento de que se trata de meras exposiciones de la ideología concreta profesada por el autor de aquéllos. Nos referimos, obviamente, a la tesis formulada, en 1926, por Triepel con la finalidad de hacer imposible que en el marco de una Democracia Constitucional, como era la Alemania de la República de Weimar, pudiera seguirse desarrollando en el ámbito universitario aquella práctica, — que, de modo inconcuso, Laband llevó a últimos extremos bajo la vigencia de la Constitución alemana de 1871 — tan característica y propia de los regímenes autoritarios, y que se explica por la obsesión que, de forma idéntica a los de los regímenes autocráticos, tienen los gobernantes de éstos por la unanimidad (C. J. Friedrich ${ }^{17}$ ) y que, en último extremo, les impide aceptar cualquier tipo de discrepancia (P. De $\mathrm{Vega}^{18}$ ), haya quien, por sus buenas relaciones con quien ocupa el poder político, pueda atribuirse la facultad de decidir, libre, caprichosa y arbitrariamente, quien desarrolla y quien no desarrolla una verdadera labor investigadora en el campo de las Ciencias Jurídicas. Y, en este sentido, la posición de Triepel no puede ser más clara, ni tampoco más contundente. A saber: frente a lo hecho, con la apelación a la «santa objetividad» y la «pureza científica», por la vieja Escuela Alemana de Derecho Público, y que, como nadie ignora, les permitió afirmar que sólo eran investigaciones científicas propios de las Ciencias Constitucionales dignas de ser tenidas en cuenta los trabajos que, versasen sobre la problemática que fuera, incluidas todas aquéllas que se corresponden con lo que Smend denominaba «Derecho técnico ordinario» — y ahí están, p. ej., aquellos escritos elaborados por Laband ${ }^{19}$ en materia en materia tributaria, y que, como a nadie puede ocultársele, tenían la única finalidad de proporcionar una cobertura científica a lo que no eran más que los intereses concretos y coyunturales del rey de Prusia/Emperador de Alemania-, realizados por los integrantes de la propia Escuela Alemana de Derecho Púbico en cuanto que, como los calificó Baldassarre ${ }^{20}$, «auténticos juristas del poder», excluyendo los formulados por los que formaban parte de cualquier otro grupo académico, lo que

15 Cfr. P. DE VEgA, «Ciencia Política e ideología», Boletín Informativo de Ciencia Política, n. 3 (1970); «Dialéctica y política», Boletín Informativo de Ciencia Política, n. ${ }^{\circ} 2$ (1969); «Gaetano Mosca y el problema de la responsabilidad social del intelectual», Boletín Informativo de Ciencia Política, n. ${ }^{\circ} 7$ (1971).

16 Cfr. K. Mannheim, Ideología y utopía. Introducción a la sociología del conocimiento, México, 1993.

17 Cfr. C. J. Friedrich, La Democracia como forma política y como forma de vida, Madrid, 1965, 2. ${ }^{\text {e ed. }}$

18 Cfr. P. DE VEGA, «Para una teoría política de la oposición», Boletín Informativo de Ciencia Política, n. ${ }^{\circ} 5(1970)$.

19 Cfr. P. Laband, Derecho presupuestario (1871), Madrid, 2012. (1994).

20 Cfr. A. Baldassarre, «Constitución y teoría de los valores», Revista de las Cortes Generales, n. 32 
proponía Triepel es que la atribución del carácter científico de cualquier ensayo realizado por un jurista se hiciera depender de que el mismo se hubiese elaborado tomando en consideración todos los saberes inherentes a la rama del Derecho que aquél pretendía cultivar. Lo que, en nuestro caso, acaba traduciéndose en aquella identificación, realizada ya Jellinek, de la Teoría del Derecho Constitucional como una de esas materias jurídicas que, por su propia esencia, se presentan, al mismo tiempo, y por igual, como unas auténticas Ciencias del Estado y Ciencias del Derecho del Estado.

Es, de cualquiera de las maneras, siguiendo la tesis de Triepel como nosotros hemos pretendido no sólo efectuar el trabajo hasta aquí hecho, sino también como pretendemos formular la respuesta al interrogante planteado por la propuesta de la Presidenta de Andalucía sobre si, pretendiendo mantenerse, o, incluso, profundizar, en la forma política «Estado Federal» o «Estado Políticamente Descentralizado», sería posible el realizar una Verfassungsänderung que tuviera por objeto la eliminación del Senado, y lo mismo da, a estos efectos, que dicha supresión se refiera tan sólo a su carácter de, ex art. 69.1, «Cámara de representación territorial», o si, por el contrario, lo que se pretende con esta revisión es configurar las Cortes Generales como un Parlamento unicameral —hipótesis ésta última que terminaría enlazando con la vieja polémica, práctica y teórica, sobre si, como, entre otros, afirmaron Barthélemy, Cooter y Riker $^{21}$, un determinado régimen jurídico-político se presenta como más democrático cuando el Parlamento se encuentra dividido en dos Cámaras, o, por el contrario, lo será más cuando el Poder Legislativo es unicameral; problemática ésta en la que, en todo caso, y siquiera sea por razones de espacio, no vamos a entrar en este trabajo- - Lo que, creemos, a nadie puede sorprender. Sobre todo, si tienen juicio de este escrito toma en consideración mi condición de discípulo del Maestro De Vega.

Situados en esta perspectiva, fácil debiera ser para todo aquél que se moleste en leer estas páginas, y, además, proceder a su valoración, comprender que, para nosotros, antes de proceder a responder de un modo concreto a la cuestión de si podría, o no podría, suprimirse el Senado español, es menester resolver una cuestión previa. Nos referimos, claro es, a la determinación de cuál de las dos posturas extremas en torno a si la existencia de la Cámara de los Estados debe ser tenida, o no, como el único elemento decisivo para la atribución de la naturaleza federal a una determinada estructura estatal, así como las repercusiones que esta consideración tiene para el ejercicio de la actividad constituyente, y tanto en el momento de la fundación o, en su caso, refundación del Cuerpo Político de que se trate, en cuyo caso quien actuará será el Constituyente en cuanto que sujeto fáctico y político-existencial que ejerce un poder absoluto, soberano e ilimitado en el contenido, material y formal, de su voluntad, como a lo largo de la vida del Estado

21 Cfr. R. D. Cooter, The Strategic Constitution, Princeton, 2000; W. RIKer, «The Justification of Bicameralism», International Political Science Review, vol. 13 (1992). 
Constitucional y siempre en condiciones de normalidad constitucional, en donde el ejercicio de aquella facultad constituyente, en cuanto que actividad reglada y limitada, le corresponde al poder de revisión en cuanto que, aunque extraordinario, poder constituido creado y ordenado por el Código Constitucional que pretende reformar, y respecto de la cual no puede llevar a cabo aquellas operaciones normativas que, en 1928, Schmitt identificó con los términos de «destrucción de la Constitución» (es decir, supresión de la Constitución existente y del Pouvoir Constituant en que se basaba) y «supresión de la Constitución» (es decir, supresión del Texto Constitucional vigente en la Comunidad Política pero manteniendo, sin embargo, el Poder Constituyente, o, si se prefiere, y por expresarlo en la fórmula utilizada por Heller y De Vega, la Constitución material, en el que aquél se basaba).

Problema éste al que, según nuestro modesto parecer — siempre, y como corresponde al estudioso del Estado, la Política y el Derecho, dubitativo y, en todo caso, siempre, y de modo inexcusable, sometido a una mejor opinión-, no ha de ser muy difícil de contestar. Lo será, en efecto, para cualquier profesional de las Ciencias del Estado y de las Ciencias del Derecho del Estado que, conocido, siguiendo la orientación metodológica empleada por La Pergola — a quien, aunque sea de manera indirecta, puedo contar entre mis Maestros, y a quien, en todo caso, se le deben, como en su día me indicó el Profesor De Vega, los acaso más brillantes estudios sobre el federalismo, y tanto a nivel estatal como a nivel internacional, elaborados en el marco geográfico de lo que hoy es la Unión Europea-, el origen histórico de las Cámaras de los centros autónomos de decisión política democrática y legítima, sea consciente de que tanto el llamado «modelo Senado» como el conocido como «modelo Consejo» hicieron su entrada en la Historia como unos patentes, innegables y manifiestos supuestos de los residuos confederantistas en las primigenias configuraciones constitucionales de los primeros Estados Federales.

Quien así lo haga no debería, a nuestro juicio, tener ninguna dificultad, y ningún problema, en aceptar que, frente a lo defendido por los, por ejemplo, Zorn, Le Fur, Smend, Mouskheli y Hesse, resulta mucho más plausible la concepción mantenida sobre este particular por Durand. Esto es, que la consideración de que la existencia de un órgano legislativo federal destinado a que las colectividades particulares participen en el proceso de toma de decisiones políticas fundamentales del Estado Federal mismo, no es ya que no sea uno de esos caracteres estructurales básicos que, verbi gratia, Wheare exigía, junto con la constitucionalización del principio federal o de autonomía, para que una determinada estructura estatal pudiera ser tenida como un auténtico Estado Políticamente Descentralizado, sino que, además, y en todo caso, aquél constituye en realidad, y en la medida en que permite diferenciarlo nítidamente del Estado Unitario, al mismo tiempo que el distinguir a las colectividades particulares de otros entes públicos territoriales, el único elemento auténticamente definidor de esta forma territorial del Estado, sino que no es, en rigor, más que en la perpetuación de una técnica 
propia y necesaria de la Staatenbund, que, recordémoslo, se define por ser una unión de Estados soberanos regida por una norma de carácter internacional (E. Borel, L. Le Fur, Ch. Durand ${ }^{22}$, etc.), a la realidad estatal que, aunque organizada asimismo de acuerdo con la técnica federal, tiene muy poco, por no decir nada, que ver con aquella forma política, como es el Bundesstaat, cuya principal característica, en cuanto que Estado Constitucional que es, es la de presentarse como una unión de ciudadanos.

Si se asume lo anterior, $-\mathrm{y}$, en nuestra opinión, no hay manera de no hacerlo_- no quedará más remedio que aceptar también como válida, naturalmente desde la lógica académica de las Ciencias Constitucionales, el resto de la construcción del insigne jurista positivista francés. De esta suerte, entendemos nosotros, tratando, aunque reconociendo expresamente que nuestro juicio está condicionado por el hecho de profesar la ideología del democratismo radical, atenernos al sabio consejo de Triepel, que no le faltaba la razón a Durand cuando afirmaba que, en cuanto que mero residuo confederantista, el Pouvoir Constituant originario en modo alguno se encontraba obligado a establecer una Cámara de los Estados. Lejos de esto, que es lo que se deriva de la tesis contraria, lo que sucede es que nos encontramos ante una materia sobre la que el Constituyente revolucionario puede decidir con total libertad. Es más, que porque lo que con su actuación hace es organizar normativamente la estructura y funcionamiento de un indiscutible Estado Constitucional, y no, y ni mucho menos, la de una Unión de Derecho Internacional, la alternativa que se presenta como el más lógica, y desde luego como más coherente con las ideas y el principio democrático, sería la de articular el Parlamento federal de tal manera que los miembros de éste representasen la voluntad de los ciudadanos en cuanto que Cuerpo Electoral de una Comunidad Política estatal única.

De idéntica manera, creemos estar en lo cierto al afirmar, con Durand, que la constitucionalización de este tipo de órganos federales puede tener una cierta justificación en aquellos supuestos en los que la Federación ha nacido como consecuencia de un paulatino y progresivo proceso de unificación y centralización de una preexistente Confederación. Lo que, en último extremo, y de acuerdo con las enseñanzas de La Pergola, se explicaría por la influencia de la Historia en las decisiones concretas adoptadas por el Pouvoir Constituant en el momento de aprobar la primera Constitución de aquellos Estados Federales. Fundamentación que, como ha de ser para todos evidente, dejaría de ser plausible incluso en el marco de estos mismos Estados Políticamente Descentralizados cuando de lo que se trate no se haya, y como en el caso anterior, de dar expresión normativa al pacto social althussiano o rousseauniano por el que se fundó la propia Comunidad Política, sino de ejercer la facultad constituyente para refundar aquéllos sobre un conjunto de principios y valores diversos a los que se consagraron en el primer rís, 1955

22 Cfr. Ch. Durand, Confédération d'États et État Fédéral. Réalisation acquises et perspectives nouvelles, Pa- 
Código Constitucional. Y si esto es así, y lo es, todavía debe ser más evidente, meridiano, indiscutible e irrefutable el que no ha de existir obligación alguna de crear y consagrar una Cámara de los centros autónomos de decisión política democrática y legítima en que pudiera aparecer dividido el Estado Federal de que se trate, cuando éste nace como consecuencia de la transformación, siempre, e inexorablemente, con la verificación de un auténtico proceso constituyente revolucionario, de un preexistente Estado Unitario. Y esto fue, como a ningún jurista, incluso aunque su objeto de atención no lo constituya el Derecho Constitucional, debiera ocultársele, lo que comprendieron perfectamente los miembros de la Constituyente española de 1931, en cuyo seno, como lo atestiguan las Actas de la misma y, en todo caso, pone de relieve Pérez Serrano ${ }^{23}$ en sus comentarios al Código Constitucional de la Segunda República, quienes, como, por ejemplo, Alcalá-Zamora ${ }^{24}$, defendieron la opción bicameral en modo alguno argumentaron su petición basándose en la futura existencia de las Regiones Autónomas, sino, por el contrario, apelando a los viejos argumentos del conservadurismo político sobre la necesidad de establecer una segunda Cámara legislativa que sirviese para corregir los posibles excesos cometidos por la otra Asamblea Legislativa.

Si desde el plano de la Teoría Constitucional del Estado Federal general y abstracto, que era en el que actuaban los Zorn, Le Fur, Smend, Mouskheli y Durand, y de la que, como, con total contundencia y acierto pleno, señaló Hesse, jamás puede prescindir el constitucionalista a la hora de abordar tanto la tarea de elaborar una Teoría Constitucional del Estado Políticamente Descentralizado concreto, como a la de enfrentarse al reto de buscar una solución determinada a cualquiera de los problemas puntuales que en este último se presentan, descendemos al terreno de la realidad jurídica y política española, se alza ante nosotros una primera conclusión, a la que no podríamos dejar de referirnos. Tanto más cuanto que, por lo menos en nuestra opinión, la misma resulta decisiva para hallar la respuesta correcta y adecuada al interrogante suscitado por la propuesta realizada por la Presidenta de la Comunidad Autónoma andaluza. Conclusión que no es otra que la de que en el momento en que se estaba desarrollando el proceso de elaboración, discusión y aprobación de la actual Constitución española, no existía motivo alguno de carácter jurídico, aunque sí, y evidentemente, de carácter ideológico, que le obligase a rechazar la propuesta de no pocos de los miembros de aquellas Cortes Constituyentes, singularmente de los que habían sido elegidos en las listas de las organizaciones que habían ejercido la oposición democrática la dictadura $^{25}$, de organizar, como ya se había hecho, por lo demás, en 1931, el Po-

23 Cfr. N. Pérez Serrano, La Constitución española (9 diciembre de 1931). Antecedentes. Texto. Comentarios, Madrid, 1932.

24 Vid. N. Alcalá-Zamora, Los defectos de la Constitución española de 1931 seguido de tres años de experiencia constitucional y de un apéndice con el texto de la Constitución de 1931, Madrid, 1981; Memorias (Segundo texto de mis Memorias), Barcelona, 1977.

25 Vid. A. Guerra, Cuando el tiempo nos alcanza. Memorias (1940-1982), Madrid, 2004. 
der Legislativo del Estado con una única Cámara: el Congreso de los Diputados, en la que estarían representados los ciudadanos españoles en tanto en cuanto se trata de los únicos sujetos del Estado español. Y ello, a pesar del dato incontrovertido de que, como escribió el Maestro De Vega ${ }^{26}$, aquel proceso constituyente de 1977-1978 se desarrolló desde la idea, aceptada mayoritariamente por los miembros de aquellas Cortes Generales, de que el proceso de institucionalización de la democracia debía traer consigo una inevitable transformación de la otrora unitaria, centralizada y centralista España en una de las múltiples manifestaciones estructurales posibles de esa realidad única a la que estamos identificando con el término de «Estado Federal» o «Estado Políticamente Descentralizado».

Dos son, de manera fundamental, los argumentos que nos conducen a esta conclusión. Motivos que, en última instancia, enlazan con la tesis de Durand y que, de una u otra suerte, se ve confirmada, como ya hemos tenido ocasión de demostrar, por las categorías puestas en circulación por La Pergola.

El primero de estos argumentos, ni que decir tiene, enlazaría con la consideración de que la Cámara de los Estados o, si se prefiere, la Cámara de los centros autónomos de decisión política democrática y legítima, lejos de ser el carácter estructural básico y absolutamente definidor de la forma política «Estado Federal», se presenta, en realidad, como un mero elemento superestructural que ni quita ni añade federalidad al sistema. De esta suerte, evidente resulta, por lo menos si actuamos desde el concepto material, y no desde el puramente formal, del Bundesstaat, que porque el refundado Estado español no iba a configurarse como un auténtico Estado Políticamente Descentralizado por la mera constitucionalización del Senado como «Cámara de representación territorial», de la misma forma que tampoco iba a dejar de ser una de las múltiples manifestaciones estructurales posibles del Estado Federal por la circunstancia de que el Legislador Constituyente hubiese decidido prescindir de aquel Senado que, no conviene olvidarlo, había hecho su entrada en escena con la Ley para la Reforma Política de 1976, con la que se procedía, sino de iure si, y desde luego, de facto, a la derogación de las siete preexistentes Leyes Fundamentales del Reino, — que siendo ciertamente normas del Derecho Público, en modo alguno, y como, entre otros, señaló Alzaga, podrían ser consideradas normas de Derecho Constitucional-, por las que se regía hasta ese momento la vida pública española (P. De Vega, P. Lucas Verdú, R. Morodo, etc.), el último Constituyente español tenía, al igual que el de cualquier otro Estado que verdaderamente sea tal, total libertad para decidir el cómo iba a articular el Poder Legislativo estatal. Lo que, traducido en otros términos, significa que podía tanto haber consagrado la existencia de una única Cámara legislativa, que, lógica e inevitablemente, se correspondería con lo que Carré denomina la Cámara Federal Popular en el contexto de las Uniones de Es-

26 Cfr. P. De Vega, «Poder Constituyente y regionalismo», en G. Trujillo (coord.) y otros, Federalismo y regionalismo, Madrid, 1979. 
tados de Derecho Constitucional, como el haber optado por establecer la división del Parlamento en dos Cámaras. Hipótesis esta última que, como a ningún jurista puede ocultársele, incluiría la doble alternativa de o bien atribuir la representación en ambas Cámaras a los ciudadanos, o bien, y por el contrario, organizarlas atribuyendo en una la elección de los representantes parlamentarios a los ciudadanos en cuanto que Pueblo del Estado Federal como unidad, y en la otra los distintos centros autónomos de decisión política democrática y legítima.

El segundo de los argumentos, por su parte, se derivaría de esa irrefutable naturaleza de mero «residuo confederantista» que, como creemos haber demostrado desde un punto de vista científico y objetivo, le corresponde siempre a las llamadas Cámaras de los Estados. Residuo confederantista que, como acabamos de ver, puede encontrar alguna justificación en los supuestos en los que el Estado Políticamente Descentralizado surge como consecuencia de la unión y progresiva centralización de una serie de Estados soberanos, independientes y miembros, por sí mismos, de la Comunidad Internacional, pero que carece de todo fundamento cuando el Estado Federal nace como consecuencia de un proceso histórico inverso al anterior. Lo que, para todos debiera ser evidente, y mucho más para los juristas, justifica sobradamente nuestra afirmación de que el Constituyente español de 1977-1978, incluso teniendo presente el que formaba parte del contenido de su voluntad soberana el permitir, con la constitucionalización de una «norma de apertura histórica» (J. Pérez Royo, F. Tomás y Valiente, J. J. González Encinar), el que España pudiera terminar configurándose como una manifestación estructural de la forma jurídico-política Estado Políticamente Descentralizado, en modo alguno estaba obligado a establecer una instancia legislativa integrada por representantes de las Comunidades Autónomas que, en ejercicio del principio dispositivo o de voluntariedad, pudieran constituirse una vez que el Código Constitucional entrase en vigor. Y ello, por la muy sencillísima razón de que, como, entre otros, puso de manifiesto el Profesor, y segundo Presidente de nuestro Tribunal Constitucional, Tomás y Valiente ${ }^{27}$, desde que hizo su entrada en la Historia, como ese producto típico del pensamiento renacentista que debe su nombre al ingenio de Nicolás de Maquiavelo $^{28}$, ninguno de los actuales centros autónomos de decisión política democrática y legítima españoles ha gozado en algún momento, y desde que en 1516 España se constituyó en una Comunidad Política única, del status de Estado soberano, independiente y sujeto, por sí mismo, del Derecho Internacional Público. Con lo que, en nuestra modesta opinión, deja sin sentido la constitucionalización de este tipo de órganos cuya finalidad su última, al decir, por ejemplo, de Le Fur y Smend, no es otra que la de permitir que con su presencia en él las colectividades particulares recuperen una parte de

27 Cfr. F. Tomás y Valiente, «Raíces y paradojas de una conciencia colectiva», en F. TomÁs y VALIENTE, Escritos sobre y desde el Tribunal Constitucional, Madrid, 1993.

28 Cfr. N. Maquiavelo, El Príncipe (1513), Madrid, 1988. 
aquella soberanía que les correspondía y que, necesariamente, perdieron al integrarse en un nuevo Estado Federal.

Porque esto es así, y enlazando de nuevo con la construcción de la Teoría Constitucional General del Estado Federal formulada por Durand, y que, como decimos, se ve confirmada por las investigaciones sobre el federalismo realizadas por el Maestro La Pergola, fácil es encontrar, actuando de una manera cabal y ponderada, y, en todo caso, desde los contenidos propios e insoslayables de las Ciencias Constitucionales, la respuesta adecuada al problema de si sería posible, como ha insinuado la Presidenta andaluza, la socialista Susana Díaz, el llevar a cabo una reforma constitucional que tuviera por objeto la supresión del Senado. Y, según nuestro parecer, ésta no puede ser sino positiva. La razón es fácilmente comprensible. Ocurre que, en la medida en que la Cámara de los Estados, en cuanto que instituto, aunque derivado de las relaciones federales, plenamente ajeno a la forma «Estado Federal», es tan sólo un elemento superestructural que en modo alguno determina la naturaleza federal o no federal de una determinada estructura estatal, evidente resulta que, situados incluso en los esquemas mentales con los que opera Hesse, supresión habría de ser reputada como una operación normativa válida, lícita y legítima en tanto en cuanto que, la misma, ni supondría, por un lado, que España dejase de ser una de las múltiples manifestaciones estructurales posibles del Estado Políticamente Descentralizado, ni, por el otro, el que con una tal revisión de la Constitución se procediese a la substitución del modelo concreto y determinado del Estado Federal, en nuestro caso, permitido por la voluntad soberana del Pouvoir Constituant por otro modelo del mismo.

Ahora bien, si esto es así, debemos advertir, y de manera inmediata, que si bien sería posible y jurídicamente aceptable el llevar a cabo una modificación formal del Código Constitucional vigente para suprimir el Senado, o una al menos, su configuración como «Cámara de las Comunidades Autónomas», y que la misma, en cuanto que una simple operación jurídica válida, lícita y legítima, habrá de ser reputada como una auténtica reforma constitucional y no, y bajo ningún concepto, como la perpetración de un auténtico fraude a la Constitución, lo que ya no sería posible es el que se aprovechara esa revisión constitucional para eliminar la participación de los centros autónomos de decisión política democrática y legítima en el proceso de toma de decisiones políticas fundamentales del Estado español en su conjunto. Y ello, por cuanto que, como muy bien comprendió Heller, es este derecho de los miembros, en su condición de unidades de decisión y acción jurídica y política parcial es que son, a integrarse en el proceso de formación de la voluntad unitaria de la Comunidad Política estatal única, lo que constituye, y no la existencia de una Cámara de los Estados, uno de esos caracteres estructurales básicos que, a la postre, permiten definir e individualizar al Estado Políticamente Descentralizado frente a otras formas de organización territorial del Estado, así como el proceder a diferenciar las colectividades particulares del resto de los entes públicos territoriales en los que puede aparecer dividido el Estado. 
Lo anterior, de todos es sobradamente conocido, encuentra ya una perfecta materialización en el Derecho Constitucional español. Desde luego, así se desprende del hecho de que el Constituyente de 1977-1978 reconociese el derecho a la iniciativa legislativa y constitucional a las autoridades políticas de las distintas comunidades-miembro que, al amparo de lo ordenado en el propio Texto Constitucional se han constituido. Mecanismo éste que, sin duda, podría todavía perfeccionarse más. A tal fin iba dirigida aquella propuesta de lege ferenda que realicé en 1994, y que se traducía en que para asegurar a las Comunidades Autónomas una mayor participación en la que, sin disputa, se presenta como la actividad normativa más importante en el contexto de un Estado Constitucional ya operante: la Verfassungsänderung, y para al mismo tiempo otorgar un sentido pleno a la exigencia de que la revisión constitucional haya de ser aprobada por el voto directo del Cuerpo Electoral, podría llevarse a cabo una modificación de la LODMR en el sentido de que el cómputo de la mayoría necesaria para la aprobación refrendataria de la reforma se hiciera siguiendo el modelo australiano, conforme al cual aquella de obtener el voto afirmativo de la mayoría de los ciudadanos como Pueblo federal, y, además, el de la mayoría de los electores en la mayoría de las colectividades particulares.

Del mismo modo, nos encontramos con que no sólo no podrían suprimirse, sino que tendrían que ser perfeccionados, todos aquellos instrumentos de cooperación que fueron ya establecidos en la original redacción del Texto de 1978. Problemática esta es la que, obviamente, no podemos detenernos, y sobre la que nos remitimos a los harto meritorios trabajos realizados al respecto por Javier Tajadura ${ }^{29}$.

No quisiera, no obstante, terminar este artículo sin hacer una observación sobre el modo en que, desde mi particular punto de vista, se lograría una correcta y adecuada articulación a la exigencia, inherente, como sabemos, a la esencia misma del Estado Federal, de que, porque en esta forma territorial del Estado el ejercicio del poder ordinario se encuentra dividido entre la organización política central y las distintas organizaciones políticas regionales, los centros autónomos de decisión política democrática y legítima deben tomar de alguna forma parte en el proceso de toma de decisiones políticas fundamentales del Estado. Se trata, obviamente, de realizar, al igual que han hecho otros muchos Profesores de Derecho del Estado españoles, y, en el marco de una Democracia Constitucional, con la misma legitimidad que éstos, una de esas propuestas conocidas con el término de «de lege ferenda» que, nadie puede ignorarlo, tan aplaudidas son cuando se realizan en el ámbito de otras ramas de las Ciencias Jurídicas, y que es, en definitiva, a lo que invitaban las concepciones sobre las Ciencias del Estado y las Ciencias del Derecho del Estado mantenidas, desde las más diversas concepciones metodoló-

29 Cfr. J. Tajadura Tejada, El principio de cooperación en el Estado Autonómico, Granada, 1998; «Cortes Generales y cooperación interautonómica», Revista de las Cortes Generales, n. ${ }^{4} 8$ (1999). 
gicas y las más distintas posiciones ideológicas, por constitucionalistas tan relevantes como lo fueron, y lo son, G. Jellinek, Heller, De Vega y Rubio Llorente.

En este sentido, indicaré que, suprimido a través de la reforma constitucional el Senado, un buen mecanismo para permitir la participación de las Comunidades Autónomas en el proceso de formación de la voluntad unitaria del Estado, lo podemos encontrar atendiendo a los debates habidos en el seno de la Constituyente de Weimar sobre este particular. Me refiero, en concreto, a aquellos que, según nos cuenta $\mathrm{W}$. Jellinek, tuvieron lugar como consecuencia de la invitación cursada por Hugo Preuss a una serie de autoridades políticas y de miembros del estamento académico a debatir con él la orientación que el propio Preuss, en cuanto que encargado, por mandato expreso del socialista Friedrich Ebert, de redactar el Proyecto de Constitución, debía dar al documento de gobierno por el que se iba a regir la naciente República alemana. En esas discusiones previas a la redacción del texto conocido como «el Proyecto original de Preuss», y bajo una más que sobresaliente influencia de los planteamientos unitaristas defendidos por Max Weber, Simmons y el propio Preuss, se planteó la posibilidad de crear un nuevo órgano tendente a facilitar aquella participación. Se trataba, en concreto, de lo que llamaron ya Reichsrat, y que nada tenía que ver en realidad ni con el viejo Bundesrath guillermino, y con el Reichsrat finalmente constitucionalizado por el Constituyente alemán de 1919. En efecto, debe tomarse en consideración que frente a la naturaleza que correspondía tanto al Bundesrath de 1871, como al Consejo Federal de 1919, de ser, con total independencia de si se entiende que los mismos formaban parte o no del Poder Legislativo federal, unos órganos deliberantes y decisorios competentes para llevar a cabo la actividad normativa, el Reichsrat inicialmente propuesto se caracterizaría por ser un órgano con funciones meramente consultivas, similar, en consecuencia, a nuestro Consejo de Estado. La principal diferencia con este último, radicaría en que mientras que el Consejo de Estado se encuentra vinculado, y de manera especial, con la actividad del Poder Ejecutivo, el Reichsrat ideado en aquellos debates celebrados del 9 al 12 de diciembre de 1918, se presentaría como un órgano de asesoramiento técnico para el desarrollo de la función legislativa del Parlamento federal.

Es tomando en consideración lo anterior, desde donde, con la mayor de las humildades, yo me atrevería a propugnar que, decidida la eliminación del Senado, acaso fuera conveniente proceder a la creación de este nuevo órgano consultivo y de apoyo al Congreso de los Diputados, el cual, para mí, debería estar integrado por representantes designados tanto por la organización política central como por las diversas organizaciones políticas regionales. Y me interesa señalar que es, justamente, en un órgano de este tipo, y en modo alguno en una institución de carácter parlamentario, donde, habida cuenta la complejidad técnica de los asuntos sobre los que ha de trabajar, cobraría pleno sentido, y además se presentaría como una alternativa democráticamente aceptable y asumible, la idea defendida por algún muy ilustre constitucionalista que presta sus servicios en alguna de las Universidades catalanas de que los miembros de esta institución 
sean reclutados, por la autoridad central o regional que se estime conveniente, no entre los prácticos de la política, que le son los que decidirán en última instancia sobre el asunto que sea en sede parlamentaria, sino entre «técnicos» en lo concerniente a la organización, funcionamiento y desarrollo de la Política, el Estado y el Derecho. Lo que, ni que decir tiene, se aparta mucho de aquello que defendió, y con gran ardor, el neoliberal tecnócrata Daniel Bell ${ }^{30}$, y que, a la postre, se concretaba en la idea de que el Estado ha de organizarse según la lógica del mundo empresarial, y que de igual suerte que en el ámbito de las empresas no son todos los trabajadores los que deciden, sino tan sólo los técnicos, en el mundo del Derecho y la política tampoco han de ser, y como se ha defendido tradicionalmente desde las posturas democráticas al menos desde Solón, todos los ciudadanos quienes decidan, sino que tal tarea a de encomendarse a una élite política, integrada por «técnicos» o «expertos» en dichas materias. Siendo, precisamente, esta circunstancia de no tener nada que ver la propuesta con el criterio marcado por Bell la que determina que la alternativa que, partiendo de lo defendido en su día por ese insigne constitucionalista al que aludimos, analizamos, nos parezca asumible y aceptable en el contexto de una Comunidad Constitucional en la que, como se establece en el vigente Derecho Constitucional español, la soberanía pertenece al Pueblo y, por ello mismo, el poder de todos sus órganos se deriva de la voluntad soberana de los ciudadanos.

$$
* * *
$$

TITLE: Could Spanish Senate be suppressed by the reform process (an early approximation to the practical problem from constitutional science

ABstRaCt: This essay studies, regarding the proposed elimination of the Senate in Spain and Italy, the legal nature of this House in the political decentralized States, confronting the thesis of Zorn, Le Fur, Smend $y$ Mouskheli and that the Durand, to arrive, finally, to a conclusion, with La Pergola, that in Germany and the United States the Bundesrath and the Senate are a waste of their confederal past, dispensable in other States.

Resumen: El presente ensayo estudia, a propósito de las propuestas de eliminación del Senado en España e Italia, la naturaleza jurídica de esta Cámara en los Estados Políticamente Descentralizados, confrontando, en concreto, las tesis de Zorn, Le Fur, Smend y Mouskbeli y las de Durand para llegar, finalmente, la conclusión, con La Pergola, de que en Alemania y Estados Unidos el Bundesrath y el Senado son un residuo confederantista, prescindible en los demás Estados.

KEY wORDS: Constitutional Law Science; Senate; Bundesratb; federalism.

Palabras Clave: Ciencia del Derecho Constitucional; Senado, Bundesrath; federalismo.

FECHA DE RECEPCIÓN: 23.05.2014

FECHA DE ACEPTACIÓN: 30.07.2014

30 Cfr. B. Bell, El fin de las ideologías (1960), Madrid, 1964. 
